\title{
GENEROAREN ERAGINA OINARRIZKO EMOZIOETAN
}

\author{
IÑAKI GAMINDE TERRAZA \\ URTZA GARAY RUIZ \\ AINTZANE ETXEBARRIA LEJARRETA \\ ASIER ROMERO ANDONEGUI \\ Euskal Herriko Unibertsitatea \\ inaki.gaminde@gmail.com \\ urtza.garay@ehu.es \\ aintzane.etxebarria@ehu.es \\ a.romero@ehu.es
}

\section{LABURPENA}

Generoa portaeratzat ulertuta eta ez hainbeste ezaugarri biologikotzat, identitatearekin lotuta dagoela esan daiteke eta uztardura horretatik genero identitatea kontzeptua sortzen da; azken honek hizkuntza-, historia- eta kultura-ezaugarriak ditu. Lan honetan, hizkuntzari dagozkion ezaugarri akustikoak eta ahots-kalitatearen ezaugarriak aztertu dira emozioen adierazpenean. Horretarako, Hego Euskal Herriko 136 informatzaile hatutatu dira eta 408 esaldiko corpusa batu da, semantikoki neutroa den esaldi bat euren barietateetan oinarrizko emozioak simulatuz adierazteko eskatu zaie. Neurketa horietatik ateratako ondorioetan, besteak beste, ikus daiteke ahos kalitatearen erabilera orokorra esanguratsuki ezberdina dela generoen arabera emozioen adierazpenean.

HITZ GAKOAK: Generoa, identitatea, ezaugarri akustikoak, ahots kalitatea, emozioak.

\section{THE RELATIONSHIP BETWEEN GENDER AND BASIC EMOTIONS}

\section{ABSTRACT}

Only by understanding gender as behavior and not as biological characteristic, it can be said that gender is attached to identity, and because of this bond the concept of gender identity is arised to a concept that has language, history and culture features. In the current paper acoustic and voice quality features related to language have been examined in the communication of emotions. For this purpose, surveys were made to 136 informants who were selected from South Basque Country, and all in all a corpus formed by 408 sentences was collected. These informants were told to repeat a semantically neutral sentence in their own language variety by simulating basic emotions. One of the results of this study, among others, shows statistically that the general use of voice quality is significantly different between two genders when emotions are being expressed.

KEYWORDS: Gender, identity, acoustic features, voice quality, emotions.

\section{SARRERA}

Oinarrizko emozioen gainean egindako aurreko lan batzuetan melodiez eta ahots kalitateaz (autorea eta lag. 2013a, 2013b) jardun dugu. Lan horietan guztietan informatzaileen ama hizkuntza eta jatorri geografikoa aldagaitzat 
erabili ziren. Oraingo honetan emozio simulatuak adieraztean, genero aldagaiak ezaugarri akustikoetan daukan garrantzia aztertu nahi dugu.

Generoa ez da maila biologikoan dagoen sexu-ezberdintasuna soilik, baizik eta portaeratzat har daiteke, izan ere, generoarekin lotutako sexuezberdintasunak ikuspegi sozialetik behin baino gehiagotan aztertuak izan dira, era horretan, genero biologikoa eta genero soziala ezberdindu daitezke eta era berean genero identitatea izeneko kontzeptura iritsi (Biemans, 2000: 11). Talbotek (2010) ere, bide beretik, generoa ikasitako portaera zela adierazi zuen aipatutako bi kontzeptuen arteko aldea areagotuz: "According to the sex/gender distinction, sex is biologically founded, whereas gender is learned behaviour. Basically, sex is a matter of genes and the secretion of hormones and the physical developments that result from them." (Talbot, 2010: 7)

Genero identitatea azaldu duten teoria asko egon dira, García-Leivak (2005) hiru bereizten ditu: soziobiologikoa, konstruktibismo soziala eta psikodinamika. Hiruretan bigarrenak defendatzen du eragin kulturala eta soziala, eta era honetan definitzen du:

De acuerdo con este planteamiento el género es una construcción del lenguaje, la historia y la cultura concreta (Hare-Mustin y Marecek, 1994) en un tiempo y en un lugar específico. Por tanto, dentro de un mismo contexto cultural pueden coexistir distintas construcciones de género (Barberá, 1998). (García-Leiva, 2005: 72).

Lan honetan hizkuntzari dagokion atalera mugatuko dugu azterketa; horrenbestez, ezaugarri akustikoak eta ahots kalitatearen erabilera aztertuko da emozioen adierazpenean generoaren arabera.

Emozioen gainerako egiten diren lanetan antzeko ezaugarri akustikoak lantzen dira (Ambruš, 2000, Makarova, eta Petrushin, 2003, Mesut Meral eta lag., 2002, Seppänen, eta lag., 2003, Liscombe, 2007, autorea, 2010, besteak beste).

Hemen aztertuko ditugun ezaugarri akustikoak lau bloke nagusitan banatu ditugu. Lehen blokean oinarrizko maiztasunari edo f0ri dagozkion melodiak, f0ren batez bestekoa eta f0ren ibiltartea aztertuko ditugu. Bigarren blokean iraupenari dagozkion esaldi osoaren iraupena eta esaldiaren azken silabaren iraupena aztertuko dira. Hirugarren blokearen azterkizunak energiaren batez bestekoa eta ibiltartea izango dira. Azkenik, laugarren blokean, ahots kalitateari dagozkion ahots murmurikatuaren eta karrankatuaren erabilerak ikusiko dira. Kasu guztietan oinarrizko emozioak (poza, tristura eta haserrea) eta informatzaileen generoa izango dira aldagaiak.

Ahots kalitateak aho-korden itxiera-motak eta bibrazio-abiadurak eragiten duten bariazioari egiten dio erreferentzia, ahots korden itxiera oso irekia bada, ahots murmurikatuari dagokio eta oso itxia bada, ahots karrankariari, tartean beste estadio batzuk daude Keatingek (2014) aurkezten duten irudi honetan ikus daitekeen bezala: 


\section{Most open Voiceless}

Most closed Glottal closure

\section{Breathy Modal Creaky}

(Keating, 2014)

Ahots kalitateak funtzio linguistikoak, ez-linguistikoak eta paralinguistikoak izan ditzake, eta azken horien bitartez hiztunaren egoera emozionala identifikatu dezakegu, ezaugarri supra-segmentalek informazio ezlinguistikoa ematen digute adinaren, generoaren edo talde sozialaren inguruan. Sarritan, hitz egitean dugun identitatea edo estiloa eraikitzen duten aztura fonetikoak geureganatzen ditugu, identitate hori, ahots kalitatearen bidez, besteak beste, murmurikatuaz edota karrankariaz baliatuz azpimarratzen da, alde batera utzi gabe hiztunek dituzten berezko anatomia aldetiko ezberdintasunak:

\footnotetext{
Voice quality can be defined as long-term, extralinguistically used suprasegmental speech characteristics. On the one hand, it is constrained by anatomical differences between speakers. On the other hand, voice quality is modulated within these physical boundaries on the grounds of sociolectal settings (preferences of the socio-cultural community) or idiosyncratic settings (personal preferences). (Biemans 2000, 21)
}

Ildo honetatik, eta jada aipatu bezala, hizkuntzak eraikitzen duen genero identitatea ikertzeko ahots-kalitatearen bariazioa aztertu da lan honetan, izan ere, norabide biko eragina da, batetik, ahots-kalitatearen bariazioa ezaugarri biologikoetan ez ezik, sozialetan oinarritzen da, eta, era berean, tasun horrek genero identitatea eraikitzen du:

Because voice quality variation has both biological and social sources, the distinction between sex (the biological difference) and gender (the socially constructed difference) as formulated by Oakley... (Biemans, 2000: 10).

Asko dira gai honen inguruan egindako lanak, alegia, ahos-kalitateak zernolako eragina duen genero identitatean, era honetara, ahots zolia ahots femeninoarekin lotzen izan da eta karrankatua maskulinoarekin (Charfuelan eta lag., 2010; Chun eta Podesva, 2010; Harness Goodwin eta lag., 2002; Lefkowitz, 2007; Lopez, 2010; Mendoza-Denton, 2007; Podesva, 2007, 2011; Sicoli, 2010; Stuart-Smith, 1999; Szakay, 2008; Yuasa, 2010, besteak beste). Ahots kalitatea hiztunen sexu joerekin lotuta ere aztertu da (Babel, 2007).

Euskararen kasuan generoak eraginiko aldaera linguistikoak adierazi dira aspaldiko lan batzuetan (Arretxe, 1994; Barrutia, 1996; autorea 2007, 2010, Zubillaga eta autorea, 2010; autorea eta autorea 2011, autorea eta lag., 2012). Lan hauetan aipatu diren aldaketak faktore sozialen menpe daude eta ez fisikoen menpe. 
Lana lau ataletan banatuta aurkezten dugu. Sarrera honen osteko bigarren atalean jaso dugun corpusa eta berau osatzeko erabili dugun metodologia aurkezten da. Hirugarren atalean datuen analisia egiten dugu. Azkenik, laugarren atalean ondorio nagusiak laburbiltzen ditugu.

\section{CORPUSA ETA METODOLOGIA}

Corpusa 408 esaldik osatzen dute; corpusa bera osatzeko 136 informatzaile eduki ditugu Hegoalde osoan.

Informatzaileak gizonezkoak $(46, \% 33,82)$ eta andrazkoak $(90, \% 66,18)$ izan dira. 1979-1993 urte bitartean jaiokoak eta denek unibertsitate ikasketak egin dituzte edo, gutxienez, unibertsitatera arteko ikasketa guztiak euskaraz egin dituzte.

Informatzaileen ama hizkuntzaren arabera talde bi ditugu; A taldea euskara ama hizkuntzatzat eduki duten informatzaileek osatzen dute eta B taldea ama hizkuntzatzat gaztelania eduki dutenek; azken hauek, hezkuntza prozesuan jabetu ziren euskararekin 2 edo 3 urterekin. A taldeko informatzaileak 77 izan dira $(\% 56,62)$ eta B taldekoak $59(\% 43,38)$.

1. taulan eduki ditugun informatzaileak probintziaka (Araba AR, Bizkaia BI, Gipuzkoa GI, eta Nafarroa NA) eta euren ama hizkuntzaren (Ah) eta generoaren (mutilak $\mathrm{M}$ eta neskak $\mathrm{N}$ ) arabera banatuta aurkezten ditugu; informatzaileen identifikaziorako euren herrien izenak erabiliko ditugu:

\begin{tabular}{|c|c|c|c|}
\hline Probintzia & $\begin{array}{c}\text { Ama } \\
\text { hizkuntza }\end{array}$ & Generoa & Informatzaileak \\
\hline \multirow{3}{*}{ AR } & $\mathbf{A}$ & $\mathbf{N}$ & Aramaio \\
\hline & \multirow[b]{2}{*}{ B } & $\mathbf{M}$ & Amurrio, Gasteiz \\
\hline & & $\mathbf{N}$ & $\begin{array}{l}\text { Amurrio, Artziniega, Laudio, Urduña, Gasteiz1, Gasteiz2, Gasteiz3, } \\
\text { Gasteiz4, Gasteiz5, Agurain, Kanpezu, Eskuernaga, Oion, Urizahar }\end{array}$ \\
\hline \multirow{4}{*}{ BI } & \multirow[b]{2}{*}{ A } & $\mathbf{M}$ & $\begin{array}{l}\text { Ajangiz, Areatza, Aulesti, Bermeo, Busturia, Galdakao, Igorre, Iurreta, } \\
\text { Lekeitio, Markina, Mungia, Ondarroa, Zornotza }\end{array}$ \\
\hline & & $\mathbf{N}$ & $\begin{array}{l}\text { Bakio, Larrabetzu, Mungia, Igorre, Lemoa, Zeanuri, Durango, Elorrio, } \\
\text { Mallabia, Bermeo, Busturia, Ereño, Gernika, Amoroto, Etxebarria, } \\
\text { Lekeitio, Ondarroa }\end{array}$ \\
\hline & \multirow{2}{*}{ B } & $\mathbf{M}$ & Berriz, Bilbo, Galdakao, Portugalete, Sestao \\
\hline & & $\mathbf{N}$ & Balmaseda, Karrantza, Basauri, Bilbo, Getxo, Sestao, Lemoa, Durango \\
\hline \multirow{4}{*}{ GI } & \multirow[b]{2}{*}{ A } & M & $\begin{array}{l}\text { Arrasate, Azkoitia, Bergara, Donostia1, Donostia2, Hernani, } \\
\text { Hondarribia, Orio, Tolosa, Zestoa, Zumaia, Zumarraga }\end{array}$ \\
\hline & & $\mathbf{N}$ & $\begin{array}{l}\text { Aretxabaleta, Bergara, Eibar, Oñati, Aizarnazabal, Azkoitia, Errezil, } \\
\text { Zarautz, Zumaia, Gabiria, Ordizia, Segura, Urretxu, Andoain, TolosaA1, } \\
\text { TolosaA2, DonostiaA1, DonostiaA2, Hernani, Lasarte, Oiartzun }\end{array}$ \\
\hline & \multirow{2}{*}{ B } & $\mathbf{M}$ & Aizarnazabal, Beasain, Donostia \\
\hline & & $\mathbf{N}$ & Elgoibar, Ordizia, Tolosa, Donostia \\
\hline \multirow{4}{*}{ NA } & \multirow[b]{2}{*}{ A } & $\mathbf{M}$ & Arbizu, Bera, Donamaria, Leitza \\
\hline & & $\mathbf{N}$ & $\begin{array}{l}\text { Bera, Ezkurra, Goizueta, Irurita, Leitza, Lekunberri, Oronoz, Urdiain, } \\
\text { Zubieta }\end{array}$ \\
\hline & \multirow[b]{2}{*}{ B } & $\mathbf{M}$ & Altsasu, Iruñea1, Iruñea2, Lizarra, Tutera1, Tutera2, Zubiri \\
\hline & & $\mathbf{N}$ & $\begin{array}{l}\text { Bera, Lesaka, Burlata, Iruñea1, Iruñea2, Iruñea3, Zizur, Iturgoien, } \\
\text { Lizarra, Agoitz, Erriberri, Irunberri, Urdaitz, Zangoza, Tutera1, Tutera2 }\end{array}$ \\
\hline \multicolumn{4}{|c|}{$\begin{array}{l}\text { 1. Taula: Eduki ditugun informatzaileak probintziaka eta euren ama hizkuntzaren eta } \\
\text { generoaren arabera sailkatuta. }\end{array}$} \\
\hline
\end{tabular}


Artikulu honetan simulatutako emozioez jardungo dugu. Datuak jaso ahal izateko informatzaileei semantikoki ezelako markarik ez daukan esaldi neutro bat euren barietateetan esateko eskatu zitzaien. Esaldia euskara estandarrean (1) izan da.

(1) Txakurra sartu da.

Behin esaldi neutroa edukiz gero, hiru egoeratan oinarrizko emozioekin esateko eskatu zitzaien (poza, tristura eta haserrea). Grabazioak 2007-2012 urte bitartean egin ziren informatzaileen ingurune naturalean. Grabazioak egiteko, aldian-aldian, hiru tresna erabili izan dira: Sony minidisc, marantz eta Zoom Hn4.

Informatzaileen datuak grabatu ondoren, bigarren urratsa testuen transkripzioa eta etiketazioa egitea izan da, horretarako "Praat" programa erabili da (Boersma eta Weenink, 2009); programa honek, jakina denez, sonogramak ikusteko aukera ematen du eta bertan markak eta etiketak jar daitezke gero script baten bidez ateratzeko. Lan honen helburua hauxe izan da: batetik, ezaugarri akustikoak zehaztea (oinarrizko maiztasuna, iraupena eta energía) eta bestetik, ahots kalitatearen analisia egitea.

\section{DAtUen ANALisia}

Datuen analisia aurkezteko atal hau lau azpi-ataletan banatuta aurkeztuko dugu. Lehen azpi-atalean oinarrizko maiztasunaren edo f0ren analisiak aurkeztuko ditugu, bigarren azpi-atalean iraupenari dagozkionak, hirugarren azpi-atalean energiaren datuak aztertuko dira eta, azkenik, laugarren azpi atalean ahots kalitateari dagozkionak.

\subsection{Oinarrizko maiztasunaren analisia}

Azpi-atal honetan, f0ri dagozkion datuekin azterketa hauek egingo ditugu; batetik, esaldiaren melodiak aztertu ditugu eta bestetik, f0ren batez bestekoa eta ibiltartea.

Jaso ditugun melodien datuen analisia aurkezteko aurreko lan batean (autorea eta lag. 2013) proposatutako sisteman oinarrituko gara. Melodiaren osagaitzat lau alde hartuko ditugu: (1) Esaldiaren gailurraren kokapena, (2) Lehen sintagmaren sakosten eta gailurren konbinazioak, (3) Aditz sintagmaren gorputzaren sakosten eta gailurren konbinazioak eta (4) Azken silabaren tonuaren gorabeherak.

Esaldi osoaren gailurra aditz aurreko sintagman edo aditzean ager daiteke; gainera, hauen barruan, edozein silabatan koka daiteke. Beronen arabera hiru aukera edukiko genituzke osagai bakoitzeko (1. grafikoa): 
(1a) Gailurra lehen sintagman, lehen silaban $(\% 1,2)$

(1b) Gailurra lehen sintagman, bigarren silaban $(\% 33,8)$

(1c) Gailurra lehen sintagman, hirugarren silaban $(\% 56,6)$

(2a) Gailurra bigarren sintagman, lehen silaban (\%1,5)

(2b) Gailurra bigarren sintagman, bigarren silaban $(\% 6,4)$

(2c) Gailurra bigarren sintagman, hirugarren silaban $(\% 0,5)$

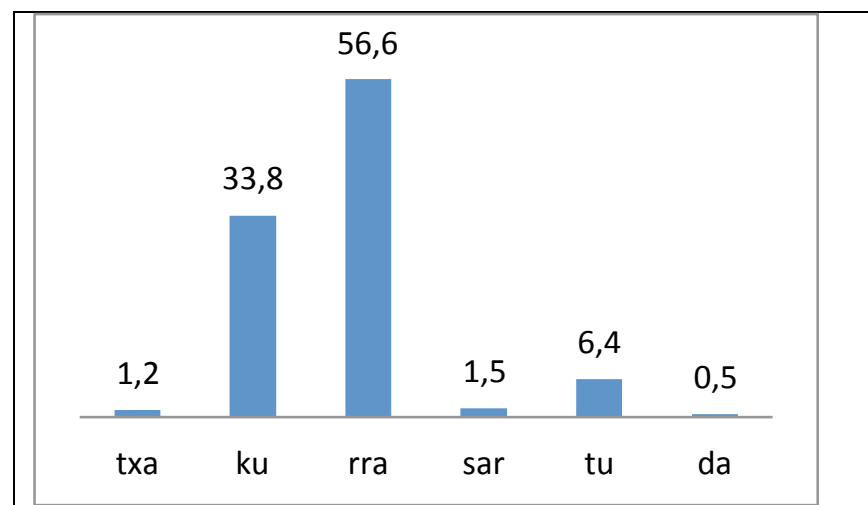

1. Grafikoa: Gailurra kokatzen den sintagmen eta silaben araberako aukerak.

1. grafikoan ikus daitekeen bezala, aukera guztien \%91,6an esaldiaren gailur prosodikoa aditz aurreko sintagman kokatzen da; aditzean \%8,4ean baino ez da gailur prosodikoa kokatzen.

Gailur prosodikoak kokatzen diren silaben portzentajeak informatzaileen generoaren arabera aztertzen baditugu (2. taula), "txa" eta "rra" silabekin izan ezik alde nabarmenak agertzen zaizkigu gainerakoetan; alde hauek estatistikoki esanguratsuak dira (balioa 14,726; askatasun mailak 5; $p=0,012$ ).

\begin{tabular}{|l|r|r|}
\hline & \multicolumn{1}{|c|}{ M } & \multicolumn{1}{|c|}{ N } \\
\hline txa & 1,45 & 1,11 \\
\hline ku & 29,71 & 35,93 \\
\hline rra & 56,52 & 56,67 \\
\hline sar & 0 & 2,22 \\
\hline tu & 10,87 & 4,07 \\
\hline da & 1,45 & 0 \\
\hline \multicolumn{2}{|c|}{ 2. Taula: Gailurra kokatzen den silaben araberako } \\
portzentajeak informatzaileen generoaren arabera.
\end{tabular}

Datuak emozioen arabera sailkatzen baditugu (3. taula), "ku" eta "rra" aukeretan alde nabarmenak agertzen zaizkigu. Hala ere, alde hauek ez dira estatistikoki esanguratsuak, khi karratuaren proba eginda (balioa $=16,715$; askatasun mailak 10; $\mathrm{p}=0,081$ ). 


\begin{tabular}{|c|c|c|c|}
\hline & haserrea & poza & tristura \\
\hline txa & 0 & 1,47 & 0 \\
\hline $\mathbf{k u}$ & 33,09 & 25,74 & 42,65 \\
\hline rra & 58,82 & 61,76 & 47,79 \\
\hline sar & 2,21 & 0,74 & 2,94 \\
\hline tu & 4,41 & 8,82 & 5,88 \\
\hline da & 0 & 1,47 & 0 \\
\hline
\end{tabular}

4. taulan emozio bakoitzaren gailurraren kokapen portzentajeak ematen ditugu generoaren arabera sailkatuta; aldeak agertzen diren arren, ez dira estatistikoki esanguratsuak (pozarekin $\mathrm{p}=0,245$; tristurarekin $\mathrm{p}=0,762$ eta haserrearekin $p=0,071$ ).

\begin{tabular}{|l|r|r|r|r|r|r|}
\hline & \multicolumn{2}{|c|}{ Poza } & \multicolumn{2}{c|}{ Tristura } & \multicolumn{2}{c|}{ Haserrea } \\
\hline & M & \multicolumn{1}{|c|}{$\mathbf{N}$} & M & \multicolumn{1}{|c|}{$\mathbf{N}$} & \multicolumn{1}{c|}{ M } & N \\
\hline txa & 2,17 & 1,11 & 0,00 & 1,11 & 2,17 & 1,11 \\
\hline ku & 26,09 & 25,56 & 39,13 & 44,44 & 23,91 & 37,78 \\
\hline rra & 54,35 & 65,56 & 50,00 & 46,67 & 60,87 & 57,78 \\
\hline sar & 0,00 & 1,11 & 2,17 & 3,33 & 2,17 & 2,22 \\
\hline tu & 13,04 & 6,67 & 8,70 & 4,44 & 10,87 & 1,11 \\
\hline da & 4,35 & 0,00 & 0,00 & 0,00 & 0,00 & 0,00 \\
\hline
\end{tabular}

4. Taula: Gailurra kokatzen den silaben araberako portzentajeak emozioen eta informatzaileen generoaren arabera.

Lehen sintagman agertzen diren sakosten eta gailurren arteko hedadurak aztertuta: (1) s-g-s, (2) s-g-g, (3) g-s-g eta (4) g-s-s. 2. grafikoan melodia bakoitzaren ehunekoak ematen ditugu orokorrean. Bertan ikusten den bezala, gehien erabiltzen dena "s-g-g" melodia da (257, \%63), bigarrena "s-g-s" da (146, $\% 35,8)$, hirugarrena "g-s-s" $(3, \% 0,7)$ eta gutxien erabiltzen dena "g-s-g" (2, $\% 0,5)$.

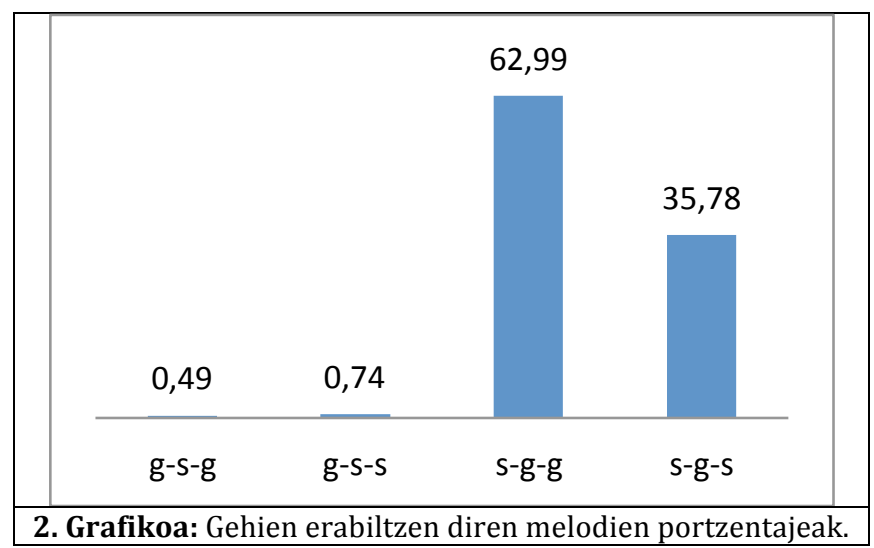

Datuak informatzaileen generoaren arabera aztertzen baditugu (5. taula), ikus dezakegu ezen, aldeak ez direla oso handiak (3. grafikoa). Agertzen diren 
aldeak txikiak dira eta ez dira estatistikoki esanguratsuak (balioa 3,344; askatasun mailak 3; $p=0,342$ ).

\begin{tabular}{|l|r|r|r|r|}
\hline & \multicolumn{2}{|c|}{ M } & \multicolumn{1}{c|}{ N } \\
\hline \multicolumn{1}{|c|}{ Melodia } & \multicolumn{1}{|c|}{ Kopurua } & Ehunekoa & \multicolumn{1}{c|}{ Kopurua } & \multicolumn{1}{c|}{ Ehunekoa } \\
\hline s-g-s & 45 & 32,61 & 101 & 37,41 \\
\hline s-g-g & 91 & 65,94 & 166 & 61,48 \\
\hline g-s-g & 0 & 0 & 2 & 0,74 \\
\hline g-s-s & 2 & 1,45 & 1 & 0,37 \\
\hline \multicolumn{5}{|c|}{ 5. Taula: Lehen sintagmaren melodiak informatzaileen generoaren arabera. } \\
\hline
\end{tabular}

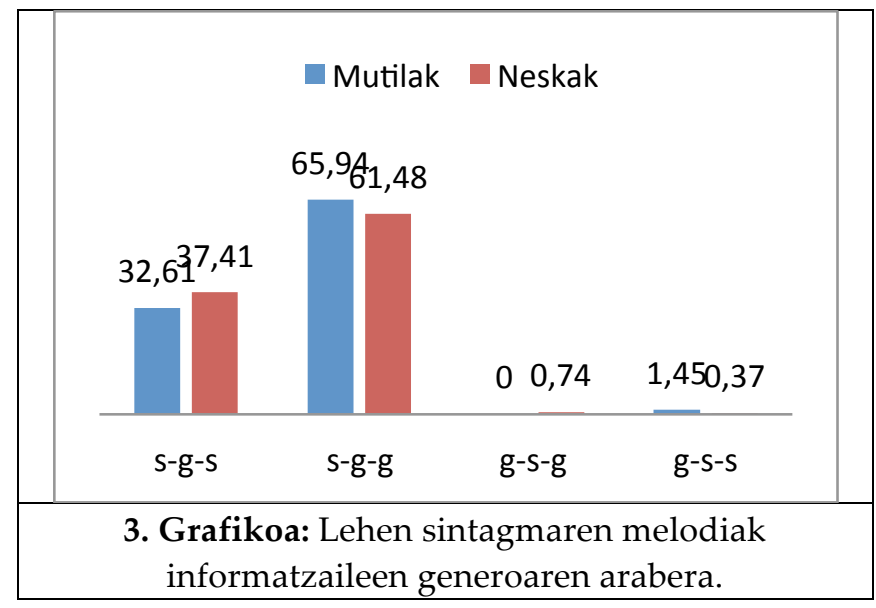

Datuak emozioen arabera sailkatzen baditugu (6. taula), portzentajerik altuenak dauzkaten aukerei erreparatuz gero, ikusten dugu ezen, "s-g-s" aukerak portzentajerik altuena tristuraren kasuan daukala eta "s-g-g" aukerak, berriz, pozean eta haserrean. Edozelan ere, khi karratuaren proba eginez gero, emaitzak ez dira estatistikoki esanguratsuak (balioa 12,320; askatasun mailak 6; $\mathrm{p}=0,055)$.

\begin{tabular}{|l|r|r|r|r|r|r|}
\hline & \multicolumn{2}{|c|}{ Poza } & \multicolumn{2}{c|}{ Tristura } & \multicolumn{2}{c|}{ Haserrea } \\
\hline & Kopurua & \multicolumn{1}{|c|}{ Ehunekoa } & \multicolumn{1}{c|}{ Kopurua } & \multicolumn{1}{c|}{ Ehunekoa } & \multicolumn{1}{c|}{ Kopurua } & Ehunekoa \\
\hline g-s-g & 0 & 0 & 1 & 0,74 & 1 & 0,74 \\
\hline g-s-s & 2 & 1,47 & 0 & 0,00 & 1 & 0,74 \\
\hline s-g-g & 96 & 70,59 & 73 & 53,68 & 88 & 64,71 \\
\hline s-g-s & 38 & 27,94 & 62 & 45,59 & 46 & 33,82 \\
\hline \multicolumn{7}{|c|}{ 6. Taula: Lehen sintagmaren melodiak emozioen arabera. } \\
\hline
\end{tabular}

7. taulan emozio bakoitzaren gailurraren kokapen portzentajeak ematen ditugu generoaren arabera sailkatuta; aldeak agertzen diren arren, ez dira estatistikoki esanguratsuak (pozarekin $p=0,884$; tristurarekin $p=0,710$ eta haserrearekin $\mathrm{p}=0,238)$. 


\begin{tabular}{|l|r|r|r|r|r|r|}
\hline & \multicolumn{2}{|c|}{ Poza } & \multicolumn{2}{c|}{ Tristura } & \multicolumn{2}{c|}{ Haserrea } \\
\hline & $\mathbf{M}$ & $\mathbf{N}$ & $\mathbf{M}$ & $\mathbf{N}$ & \multicolumn{1}{c|}{$\mathbf{M}$} & $\mathbf{N}$ \\
\hline g-s-g & 0 & 0,00 & 0,00 & 1,11 & 0,00 & 1,11 \\
\hline g-s-s & 2,17 & 1,11 & 0,00 & 0,00 & 2,17 & 0,00 \\
\hline s-g-g & 69,57 & 71,11 & 56,52 & 52,22 & 71,74 & 61,11 \\
\hline s-g-s & 28,26 & 27,78 & 43,48 & 46,67 & 26,09 & 37,78 \\
\hline \multicolumn{7}{|c|}{ 7. Taula: Lehen sintagmaren melodiak emozioen eta informatzaileen generoaren arabera. } \\
\hline
\end{tabular}

Esaldiaren bigarren sintagmaren gorputzean ager daitezkeen sakosten eta gailurren konbinazioak bost dira (4. grafikoa): "g-g" (4, \%1), "g-s" (9, \%2,2), "ggs" $(1, \% 0,2)$, “s-g" $(259, \% 63,5)$ eta "s-s" $(135, \% 33,1)$.

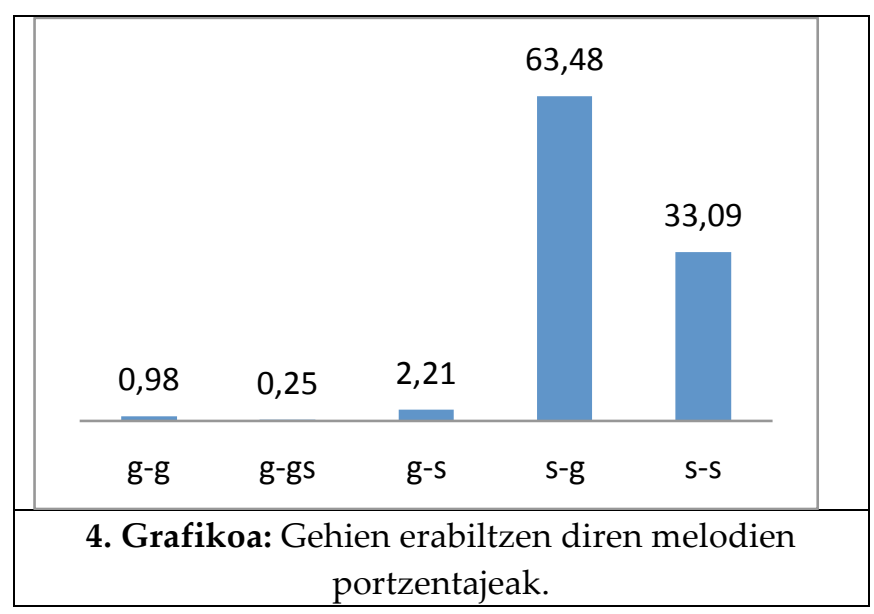

8. taulan melodia bakoitzaren kopuruak eta portzentajeak erakusten dira informatzaileen generoaren arabera. Agertzen diren aldeak estatistikoki esanguratsuak dira (balioa $=26,163$; askatasun mailak 4; $\mathrm{p}=0,000$ ).

\begin{tabular}{|l|r|r|r|r|}
\hline & \multicolumn{2}{|c|}{ M } & \multicolumn{2}{c|}{$\mathbf{N}$} \\
\hline \multicolumn{1}{|c|}{ Melodia } & Kopurua & Ehunekoa & Kopurua & Ehunekoa \\
\hline g-g & 1 & 0,72 & 3 & 1,11 \\
\hline g-gs & 0 & 0,00 & 1 & 0,37 \\
\hline g-s & 2 & 1,45 & 7 & 2,59 \\
\hline s-g & 111 & 80,43 & 148 & 54,81 \\
\hline s-s & 24 & 17,39 & 111 & 41,11 \\
\hline \multicolumn{5}{|r|}{ 8. Taula: Bigarren sintagmaren gorputzaren melodiak informatzaileen generoaren } \\
arabera. \\
\hline
\end{tabular}

Datuak emozioen arabera sailkatzen baditugu (9. taula), portzentajerik altuenak dauzkaten aukerei erreparatuz gero, ikusten dugu ezen, "s-g" aukerak portzentajerik altuena tristuraren kasuan daukala eta baita "s-s" aukerak ere. Edozelan ere, khi karratuaren proba eginez gero, emaitzak ez dira estatistikoki esanguratsuak (balioa 7,654; askatasun mailak 8; $p=0,468$ ). 


\begin{tabular}{|l|r|r|r|r|r|r|}
\hline & \multicolumn{2}{|c|}{ Poza } & \multicolumn{2}{c|}{ Tristura } & \multicolumn{2}{c|}{ Haserrea } \\
\hline & Kopurua & Ehunekoa & \multicolumn{1}{|c|}{ Kopurua } & \multicolumn{1}{c|}{ Ehunekoa } & \multicolumn{1}{c|}{ Kopurua } & Ehunekoa \\
\hline g-g & 2 & 1,47 & 2 & 1,47 & 0 & 0 \\
\hline g-gs & 1 & 0,74 & 0 & 0,00 & 0 & 0 \\
\hline g-s & 1 & 0,74 & 5 & 3,68 & 3 & 2,21 \\
\hline s-g & 87 & 63,97 & 81 & 59,56 & 91 & 66,91 \\
\hline s-s & 45 & 33,09 & 48 & 35,29 & 42 & 30,88 \\
\hline \multicolumn{7}{|c|}{ 9. Taula: Bigarren sintagmaren gorputzaren melodiak emozioen arabera. } \\
\hline
\end{tabular}

10. taulan emozio bakoitzaren gailurraren kokapen portzentajeak ematen ditugu generoaren arabera sailkatuta; agertzen diren aldeak haserrearen kasuan baino ez dira estatistikoki esanguratsuak (pozarekin $\mathrm{p}=0,065$; tristurarekin $\mathrm{p}=$ $0,176$ eta haserrearekin $p=0,000)$.

\begin{tabular}{|l|r|r|r|r|r|r|}
\hline & \multicolumn{2}{|c|}{ Poza } & \multicolumn{2}{c|}{ Tristura } & \multicolumn{2}{c|}{ Haserrea } \\
\hline & $\mathbf{M}$ & $\mathbf{N}$ & $\mathbf{M}$ & $\mathbf{N}$ & \multicolumn{1}{|c|}{$\mathbf{M}$} & $\mathbf{N}$ \\
\hline g-g & 0 & 2,22 & 2,17 & 1,11 & 2,17 & 2,22 \\
\hline g-gs & 0 & 1,11 & 0,00 & 0,00 & 0,00 & 0,00 \\
\hline g-s & 0 & 1,11 & 2,17 & 4,44 & 0,00 & 0,00 \\
\hline s-g & 80,43 & 55,56 & 71,74 & 53,33 & 89,13 & 55,56 \\
\hline s-s & 19,57 & 40 & 23,91 & 41,11 & 8,70 & 42,22 \\
\hline
\end{tabular}

10. Taula: Bigarren sintagmaren gorputzaren melodiak emozioen eta informatzaileen generoaren arabera.

Azken silabaren tonu gorabeheretan agertu zaizkigun aukerak lau izan dira (3. grafikoa): "g" (46, \%11,27), "s" (270, \%66,18), "gs" (89, \%21,81) eta sg (3, $\% 0,74)$. 11. taulan informatzaileen generoaren arabera sailkatuta ematen ditugu. Agertzen diren aldeak estatistikoki esanguratsuak dira (balioa $=13,135$; askatasun mailak 3; $\mathrm{p}=0,004)$.

\begin{tabular}{|l|r|r|r|r|}
\hline & \multicolumn{2}{|c|}{ M } & \multicolumn{2}{c|}{ N } \\
\hline \multicolumn{1}{|c|}{ Melodia } & \multicolumn{1}{|c|}{ Kopurua } & \multicolumn{1}{c|}{ Ehunekoa } & \multicolumn{1}{c|}{ Kopurua } & \multicolumn{1}{c|}{ Ehunekoa } \\
\hline g & 10 & 7,25 & 69 & 13,33 \\
\hline gs & 20 & 14,49 & 164 & 25,56 \\
\hline s & 106 & 76,81 & 1 & 60,74 \\
\hline sg & 2 & 1,45 & 0,37 \\
\hline
\end{tabular}

11. Taula: Azken silabaren tonu gorabeheren portzentajeak informatzaileen generoaren arabera.

Datuak emozioen arabera sailkatzen baditugu (12. taula), portzentajerik altuenak dauzkaten aukerei erreparatuz gero, ikusten dugu ezen, "s" aukerak portzentajerik altuena haserrearen kasuan daukala eta " $\mathrm{g}$ " eta "gs" aukerek, berriz, pozarekin. Khi karratuaren proba eginez gero, emaitzak estatistikoki esanguratsuak dira (balioa 15,233; askatasun mailak 6; $p=0,019$ ). 


\begin{tabular}{|l|r|r|r|r|r|r|}
\hline & \multicolumn{2}{|c|}{ Poza } & \multicolumn{2}{c|}{ Tristura } & \multicolumn{2}{c|}{ Haserrea } \\
\hline & Kopurua & \multicolumn{1}{|c|}{ Ehunekoa } & \multicolumn{1}{|c|}{ Kopurua } & \multicolumn{1}{c|}{ Ehunekoa } & \multicolumn{1}{l|}{ Kopurua } & Ehunekoa \\
\hline $\mathbf{g}$ & 19 & 13,97 & 18 & 13,24 & 9 & 6,62 \\
\hline $\mathbf{g s}$ & 36 & 26,47 & 23 & 16,91 & 30 & 22,06 \\
\hline $\mathbf{s}$ & 78 & 57,35 & 95 & 69,85 & 97 & 71,32 \\
\hline sg & 3 & 2,21 & 0 & 0 & 0 & 0 \\
\hline \multicolumn{7}{|r}{ 12. Taula: Azken silabaren tonu gorabeheren portzentajeak emozioen arabera. } \\
\hline
\end{tabular}

13. taulan emozio bakoitzaren gailurraren kokapen portzentajeak ematen ditugu generoaren arabera sailkatuta; agertzen diren aldeak ez dira estatistikoki esanguratsuak (pozarekin $p=0,150$; tristurarekin $p=0,065$ eta haserrearekin $p=$ $0,168)$.

\begin{tabular}{|l|r|r|r|r|r|r|}
\hline & \multicolumn{2}{|c|}{ Poza } & \multicolumn{2}{c|}{ Tristura } & \multicolumn{2}{c|}{ Haserrea } \\
\hline & M & \multicolumn{1}{|c|}{$\mathbf{N}$} & \multicolumn{1}{c|}{ M } & \multicolumn{1}{c|}{ N } & \multicolumn{1}{c|}{ M } & \multicolumn{1}{c|}{ N } \\
\hline g & 10,87 & 15,56 & 8,70 & 15,56 & 2,17 & 8,89 \\
\hline gs & 17,39 & 31,11 & 8,70 & 21,11 & 17,39 & 24,44 \\
\hline s & 67,39 & 52,22 & 82,61 & 63,33 & 80,43 & 66,67 \\
\hline sg & 4,35 & 1,11 & 0,00 & 0,00 & 0,00 & 0,00 \\
\hline
\end{tabular}

13 Taula: Azken silabaren tonu gorabeheren portzentajeak emozioen eta informatzaileen generoaren arabera.

Azkenik esaldi osoaren melodiak sailkatuko ditugu. Horretarako esaldi osoaren gailur prosodikoa zein silabatan kokatzen den ikusiko dugu eta beronekin batera zeintzuk diren konbinatzen diren lehen eta bigarren sintagmen melodiak. Jarraian konbinazio posible guztiak aurkezten ditugu gailur prosodikoa kokatzen den silabaren eta informatzaileen arabera1 (14. taula).

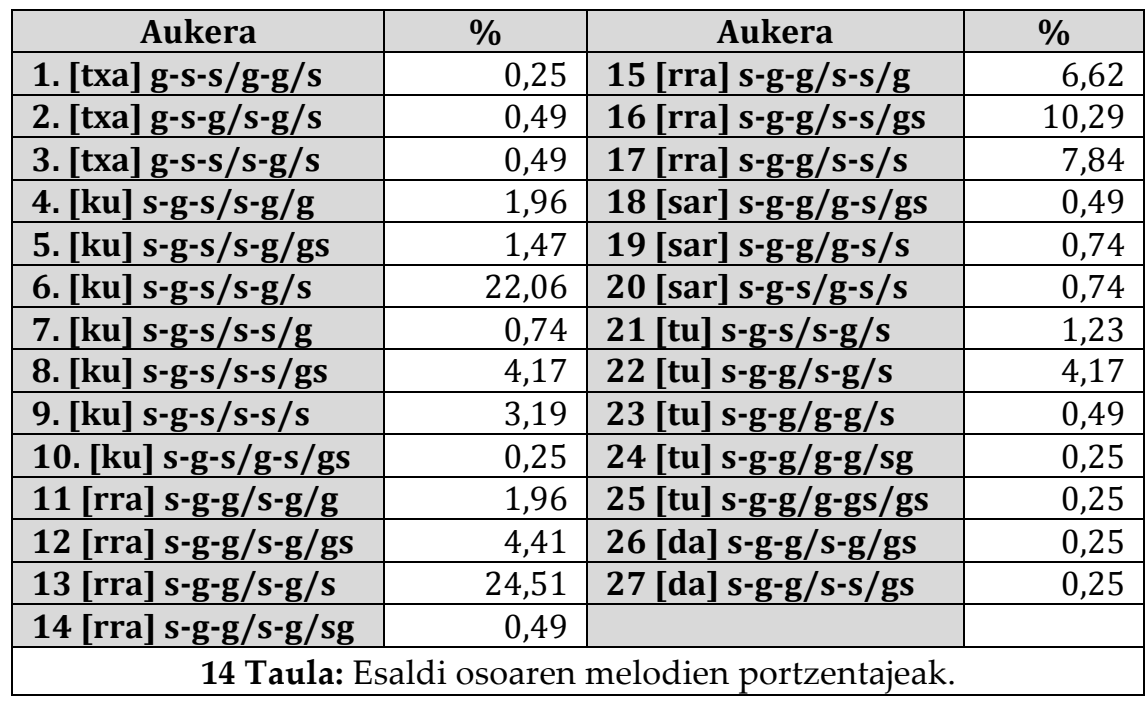

14. taulan ikusten den moduan, aukera batzuek oso portzentaje txikiak dauzkate. Portzentajerik altuenak dauzkaten aukerek (15, 17, 16, 6 eta 13) guztien $\% 71,32$ suposatzen dute. Aukera hauetan guztietan esaldi osoaren

1 "l" ikurraren bidez esaldiaren osagaiak bereiziko ditugu: lehen sintagmaren melodia, bigarren sintagmaren gorputza eta beronen azken silaba. 
gailur prosodikoa lehen sintagman kokatzen da eta, (6) aukeran izan ezik, sintagmaren azken silaban gainera.

Informatzaileen generoaren arabera agertzen den melodia banaketa (15. taula) estatistikoki esanguratsua da khi karratuaren probaren arabera (balioa 56,582, askatasun mailak 26, $\mathrm{p}=0,000)$. Emozioen araberako banaketan (16. taula) agertzen diren aldeak, ostera, ez dira estatistikoki esanguratsuak (balioa 58,474; askatasun mailak 52; $\mathrm{p}=0,250)$.

\begin{tabular}{|c|c|c|c|c|c|}
\hline Aukera & M & $\mathbf{N}$ & Aukera & M & $\mathbf{N}$ \\
\hline 1. $[\mathrm{txa}] \mathrm{g}-\mathrm{s}-\mathrm{s} / \mathrm{g}-\mathrm{g} / \mathrm{s}$ & 0 & 0,37 & 15 [rra] s-g-g/s-s/g & 2,90 & 8,52 \\
\hline 2. [txa] g-s-g/s-g/s & 0 & 0,74 & 16 [rra] s-g-g/s-s/gs & 5,07 & 12,96 \\
\hline 3. $[\mathrm{txa}] \mathrm{g}-\mathrm{s}-\mathrm{s} / \mathrm{s}-\mathrm{g} / \mathrm{s}$ & 1,45 & 0 & 17 [rra] s-g-g/s-s/s & 7,25 & 8,15 \\
\hline 4. $[\mathrm{ku}] \mathrm{s}-\mathrm{g}-\mathrm{s} / \mathrm{s}-\mathrm{g} / \mathrm{g}$ & 2,17 & 1,85 & 18 [sar] s-g-g/g-s/gs & 0 & 0,74 \\
\hline 5. $[\mathrm{ku}] \mathrm{s}-\mathrm{g}-\mathrm{s} / \mathrm{s}-\mathrm{g} / \mathrm{gs}$ & 2,17 & 1,11 & 19 [sar] s-g-g/g-s/s & 0 & 1,11 \\
\hline 6. $[\mathrm{ku}] \mathrm{s}-\mathrm{g}-\mathrm{s} / \mathrm{s}-\mathrm{g} / \mathrm{s}$ & 23,91 & 21,11 & 20 [sar] s-g-s/g-s/s & 1,45 & 0,37 \\
\hline 7. $[\mathrm{ku}] \mathrm{s}-\mathrm{g}-\mathrm{s} / \mathrm{s}-\mathrm{s} / \mathrm{g}$ & 0 & 1,11 & $21[\mathrm{tu}] \mathrm{s}-\mathrm{g}-\mathrm{s} / \mathrm{s}-\mathrm{g} / \mathrm{s}$ & 1,45 & 1,11 \\
\hline 8. $[\mathrm{ku}] \mathrm{s}-\mathrm{g}-\mathrm{s} / \mathrm{s}-\mathrm{s} / \mathrm{gs}$ & 0 & 6,30 & $22[\mathrm{tu}] \mathrm{s}-\mathrm{g}-\mathrm{g} / \mathrm{s}-\mathrm{g} / \mathrm{s}$ & 8,70 & 1,85 \\
\hline 9. $[\mathrm{ku}] \mathrm{s}-\mathrm{g}-\mathrm{s} / \mathrm{s}-\mathrm{s} / \mathrm{s}$ & 1,45 & 4,07 & $23[\mathrm{tu}] \mathrm{s}-\mathrm{g}-\mathrm{g} / \mathrm{g}-\mathrm{g} / \mathrm{s}$ & 0,72 & 0,37 \\
\hline 10. $[\mathrm{ku}] \mathrm{s}-\mathrm{g}-\mathrm{s} / \mathrm{g}-\mathrm{s} / \mathrm{gs}$ & 0 & 0,37 & 24 [tu] s-g-g/g-g/sg & 0 & 0,37 \\
\hline 11 [rra] s-g-g/s-g/g & 2,17 & 1,85 & 25 [tu] s-g-g/g-gs/gs & 0 & 0,37 \\
\hline 12 [rra] s-g-g/s-g/gs & 5,80 & 3,70 & 26 [da] s-g-g/s-g/gs & 0,72 & 0 \\
\hline 13 [rra] s-g-g/s-g/s & 30,43 & 21,48 & 27 [da] s-g-g/s-s/gs & 0,72 & 0 \\
\hline $14[\mathrm{rra}] \mathrm{s}-\mathrm{g}-\mathrm{g} / \mathrm{s}-\mathrm{g} / \mathrm{sg}$ & 1,45 & 0 & & & \\
\hline
\end{tabular}

\begin{tabular}{|c|c|c|c|c|c|c|c|}
\hline Aukera & Poza & Tristura & Haserrea & Aukera & Poza & Tristura & Haserrea \\
\hline $\begin{array}{l}\text { 1. [txa] g-s- } \\
\text { s/g-g/s }\end{array}$ & 0,74 & 0 & 0 & $\begin{array}{l}15 \text { [rra] s-g- } \\
\text { g/s-s/g }\end{array}$ & 8,82 & 7,35 & 3,68 \\
\hline $\begin{array}{l}\text { 2. [txa] g-s- } \\
\mathrm{g} / \mathrm{s}-\mathrm{g} / \mathrm{s}\end{array}$ & 0 & 0,74 & 0,74 & $\begin{array}{l}16 \text { [rra] s-g- } \\
\mathrm{g} / \mathrm{s}-\mathrm{s} / \mathrm{gs}\end{array}$ & 13,24 & 7,35 & 10,29 \\
\hline $\begin{array}{l}\text { 3. [txa] g-s- } \\
\text { s/s-g/s }\end{array}$ & 0,74 & 0 & 0,74 & $\begin{array}{l}17 \text { [rra] s-g- } \\
\mathrm{g} / \mathrm{s}-\mathrm{s} / \mathrm{s}\end{array}$ & 5,88 & 9,56 & 8,09 \\
\hline $\begin{array}{l}\text { 4. [ku] s-g- } \\
\text { s/s-g/g }\end{array}$ & 0,74 & 2,94 & 0,74 & $\begin{array}{l}18 \text { [sar] s-g- } \\
\mathrm{g} / \mathrm{g}-\mathrm{s} / \mathrm{gs}\end{array}$ & 0,74 & 0,74 & 0 \\
\hline $\begin{array}{l}\text { 5. [ku] s-g- } \\
\text { s/s-g/gs }\end{array}$ & 2,21 & 2,94 & 0,74 & $\begin{array}{l}19 \text { [sar] s-g- } \\
\text { g/g-s/s }\end{array}$ & 0 & 0,74 & 1,47 \\
\hline $\begin{array}{l}\text { 6. [ku] s-g- } \\
\text { s/s-g/s }\end{array}$ & 18,38 & 25 & 22,79 & $\begin{array}{l}20 \text { [sar] s-g- } \\
\text { s/g-s/s }\end{array}$ & 0 & 1,47 & 0,74 \\
\hline $\begin{array}{l}\text { 7. [ku] s-g- } \\
\text { s/s-s/g }\end{array}$ & 0 & 1,47 & 0,74 & $\begin{array}{l}21 \text { [tu] s-g- } \\
\text { s/s-g/s }\end{array}$ & 2,21 & 1,47 & 0 \\
\hline $\begin{array}{l}\text { 8. [ku] s-g- } \\
\text { s/s-s/gs }\end{array}$ & 3,68 & 4,41 & 4,41 & $\begin{array}{l}22 \text { [tu] s-g- } \\
\mathrm{g} / \mathrm{s}-\mathrm{g} / \mathrm{s}\end{array}$ & 5,15 & 2,94 & 4,41 \\
\hline $\begin{array}{l}\text { 9. [ku] s-g- } \\
\text { s/s-s/s }\end{array}$ & 0,74 & 5,15 & 3,68 & $\begin{array}{l}23 \text { [tu] s-g- } \\
\mathrm{g} / \mathrm{g}-\mathrm{g} / \mathrm{s}\end{array}$ & 0 & 1,47 & 0 \\
\hline $\begin{array}{l}\text { 10. [ku] s-g- } \\
\text { s/g-s/gs }\end{array}$ & 0 & 0,74 & 0 & $\begin{array}{l}24 \text { [tu] s-g- } \\
\text { g/g-g/sg }\end{array}$ & 0,74 & 0 & 0 \\
\hline $\begin{array}{l}11 \text { [rra] s-g- } \\
\mathrm{g} / \mathrm{s}-\mathrm{g} / \mathrm{g}\end{array}$ & 2,94 & 1,47 & 1,47 & $\begin{array}{l}25 \text { [tu] s-g- } \\
\text { g/g-gs/gs }\end{array}$ & 0,74 & 0 & 0 \\
\hline $\begin{array}{l}12 \text { [rra] s-g- } \\
\mathrm{g} / \mathrm{s}-\mathrm{g} / \mathrm{gs}\end{array}$ & 5,88 & 0,74 & 6,62 & $\begin{array}{l}26 \text { [da] s-g- } \\
\mathrm{g} / \mathrm{s}-\mathrm{g} / \mathrm{gs}\end{array}$ & 0,74 & 0 & 0 \\
\hline $\begin{array}{l}13 \text { [rra] s-g- } \\
\mathrm{g} / \mathrm{s}-\mathrm{g} / \mathrm{s}\end{array}$ & 23,53 & 21,32 & 28,68 & $\begin{array}{l}27 \text { [da] s-g- } \\
\text { g/s-s/gs }\end{array}$ & 0,74 & 0 & 0 \\
\hline $\begin{array}{l}14 \text { [rra] s-g- } \\
\mathrm{g} / \mathrm{s}-\mathrm{g} / \mathrm{sg}\end{array}$ & 1,47 & 0 & 0 & & & & \\
\hline
\end{tabular}


17., 18. eta 19. tauletan emozio bakoitzeko agertu zaizkigun melodien portzentajeak ematen ditugu generoaren arabera. Taula horietan agertzen den moduan, melodia guztiak ez dira emozio guztiekin agertzen; pozarekin 21 $(\% 77,78)$, tristurarekin $20(\% 74,07)$ eta haserrearekin $16(\% 59,26)$ agertzen dira. Bestalde, pozarekin (balioa 26,443; askatasun mailak 20; $p=0,152$ ) eta tristurarekin (balioa 14,429; askatasun mailak 19; $\mathrm{p}=0,758$ ) aldeak ez dira estatistikoki esanguratsuak eta haserrearekin, ostera, bai (balioa 31,589; askatasun mailak 16; $\mathrm{p}=0,011$ ).

\begin{tabular}{|c|c|c|c|c|c|}
\hline Aukera & $\mathbf{M}$ & $\mathbf{N}$ & Aukera & $\mathbf{M}$ & $\mathbf{N}$ \\
\hline 1. [txa] g-s-s/g-g/s & 0,00 & 1,11 & 15 [rra] s-g-g/s-s/g & 4,35 & 11,11 \\
\hline 2. $[\mathrm{txa}] \mathrm{g}-\mathrm{s}-\mathrm{g} / \mathrm{s}-\mathrm{g} / \mathrm{s}$ & - & - & 16 [rra] s-g-g/s-s/gs & 6,52 & 16,67 \\
\hline 3. [txa] g-s-s/s-g/s & 2,17 & 0,00 & 17 [rra] s-g-g/s-s/s & 6,52 & 5,56 \\
\hline 4. [ku] s-g-s/s-g/g & 2,17 & 2,22 & 18 [sar] s-g-g/g-s/gs & 0,00 & 1,11 \\
\hline 5. $[\mathrm{ku}] \mathrm{s}-\mathrm{g}-\mathrm{s} / \mathrm{s}-\mathrm{g} / \mathrm{gs}$ & 2,17 & 0,00 & 19 [sar] s-g-g/g-s/s & - & - \\
\hline 6. $[\mathrm{ku}] \mathrm{s}-\mathrm{g}-\mathrm{s} / \mathrm{s}-\mathrm{g} / \mathrm{s}$ & 21,74 & 16,67 & 20 [sar] s-g-s/g-s/s & - & \\
\hline 7. $[\mathrm{ku}] \mathrm{s}-\mathrm{g}-\mathrm{s} / \mathrm{s}-\mathrm{s} / \mathrm{g}$ & 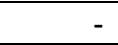 & - & $21[\mathrm{tu}] \mathrm{s}-\mathrm{g}-\mathrm{s} / \mathrm{s}-\mathrm{g} / \mathrm{s}$ & 2,17 & 2,22 \\
\hline 8. $[\mathrm{ku}] \mathrm{s}-\mathrm{g}-\mathrm{s} / \mathrm{s}-\mathrm{s} / \mathrm{gs}$ & 0,00 & 5,56 & $22[\mathrm{tu}] \mathrm{s}-\mathrm{g}-\mathrm{g} / \mathrm{s}-\mathrm{g} / \mathrm{s}$ & 10,87 & 2,22 \\
\hline 9. $[\mathrm{ku}] \mathrm{s}-\mathrm{g}-\mathrm{s} / \mathrm{s}-\mathrm{s} / \mathrm{s}$ & 0,00 & 1,11 & $23[\mathrm{tu}] \mathrm{s}-\mathrm{g}-\mathrm{g} / \mathrm{g}-\mathrm{g} / \mathrm{s}$ & - & - \\
\hline 10. [ku] s-g-s/g-s/gs & & - & $24[\mathrm{tu}] \mathrm{s}-\mathrm{g}-\mathrm{g} / \mathrm{g}-\mathrm{g} / \mathrm{sg}$ & 0,00 & 1,11 \\
\hline 11 [rra] s-g-g/s-g/g & 4,35 & 2,22 & $25[\mathrm{tu}] \mathrm{s}-\mathrm{g}-\mathrm{g} / \mathrm{g}-\mathrm{gs} / \mathrm{gs}$ & 0,00 & 1,11 \\
\hline 12 [rra] s-g-g/s-g/gs & 4,35 & 6,67 & 26 [da] s-g-g/s-g/gs & 2,17 & 0,00 \\
\hline 13 [rra] s-g-g/s-g/s & 23,91 & 23,33 & 27 [da] s-g-g/s-s/gs & 2,17 & 0,00 \\
\hline 14 [rra] s-g-g/s-g/sg & 4,35 & 0,00 & & & \\
\hline
\end{tabular}

\begin{tabular}{|c|c|c|c|c|c|}
\hline Aukera & M & $\mathbf{N}$ & Aukera & $\mathbf{M}$ & $\mathbf{N}$ \\
\hline 1. [txa] g-s-s/g-g/s & - & - & 15 [rra] s-g-g/s-s/g & 4,35 & 8,89 \\
\hline 2. $[\mathrm{txa}] \mathrm{g}-\mathrm{s}-\mathrm{g} / \mathrm{s}-\mathrm{g} / \mathrm{s}$ & 0 & 1,11 & $16[\mathrm{rra}] \mathrm{s}-\mathrm{g}-\mathrm{g} / \mathrm{s}-\mathrm{s} / \mathrm{gs}$ & 4,35 & 8,89 \\
\hline 3. [txa] g-s-s/s-g/s & - & 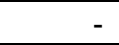 & 17 [rra] s-g-g/s-s/s & 10,87 & 8,89 \\
\hline 4. $[\mathrm{ku}] \mathrm{s}-\mathrm{g}-\mathrm{s} / \mathrm{s}-\mathrm{g} / \mathrm{g}$ & 4,35 & 2,22 & 18 [sar] s-g-g/g-s/gs & 0 & 1,11 \\
\hline 5. [ku] s-g-s/s-g/gs & 4,35 & 2,22 & 19 [sar] s-g-g/g-s/s & 0 & 1,11 \\
\hline 6. $[\mathrm{ku}] \mathrm{s}-\mathrm{g}-\mathrm{s} / \mathrm{s}-\mathrm{g} / \mathrm{s}$ & 26,09 & 24,44 & 20 [sar] s-g-s/g-s/s & 2,17 & 1,11 \\
\hline 7. $[\mathrm{ku}] \mathrm{s}-\mathrm{g}-\mathrm{s} / \mathrm{s}-\mathrm{s} / \mathrm{g}$ & 0 & 2,22 & $21[t u] s-g-s / s-g / s$ & 2,17 & 1,11 \\
\hline 8. $[\mathrm{ku}] \mathrm{s}-\mathrm{g}-\mathrm{s} / \mathrm{s}-\mathrm{s} / \mathrm{gs}$ & 0 & 6,67 & $22[\mathrm{tu}] \mathrm{s}-\mathrm{g}-\mathrm{g} / \mathrm{s}-\mathrm{g} / \mathrm{s}$ & 4,35 & 2,22 \\
\hline 9. $[\mathrm{ku}] \mathrm{s}-\mathrm{g}-\mathrm{s} / \mathrm{s}-\mathrm{s} / \mathrm{s}$ & 4,35 & 5,56 & $23[\mathrm{tu}] \mathrm{s}-\mathrm{g}-\mathrm{g} / \mathrm{g}-\mathrm{g} / \mathrm{s}$ & 2,17 & 1,11 \\
\hline 10. $[\mathrm{ku}] \mathrm{s}-\mathrm{g}-\mathrm{s} / \mathrm{g}-\mathrm{s} / \mathrm{gs}$ & 0 & 1,11 & $24[\mathrm{tu}] \mathrm{s}-\mathrm{g}-\mathrm{g} / \mathrm{g}-\mathrm{g} / \mathrm{sg}$ & - & - \\
\hline 11 [rra] s-g-g/s-g/g & 0 & 2,22 & 25 [tu] s-g-g/g-gs/gs & - & - \\
\hline $12[\mathrm{rra}] \mathrm{s}-\mathrm{g}-\mathrm{g} / \mathrm{s}-\mathrm{g} / \mathrm{gs}$ & 0 & 1,11 & 26 [da] s-g-g/s-g/gs & - & - \\
\hline 13 [rra] s-g-g/s-g/s & 30,43 & 16,67 & 27 [da] s-g-g/s-s/gs & - & - \\
\hline 14 [rra] s-g-g/s-g/sg & - & & & & \\
\hline
\end{tabular}




\begin{tabular}{|c|c|c|c|c|c|}
\hline Aukera & M & $\mathbf{N}$ & Aukera & M & $\mathbf{N}$ \\
\hline 1. $[\mathrm{txa}] \mathrm{g}-\mathrm{s}-\mathrm{s} / \mathrm{g}-\mathrm{g} / \mathrm{s}$ & - & - & 15 [rra] s-g-g/s-s/g & 0 & 5,56 \\
\hline 2. $[\mathrm{txa}] \mathrm{g}-\mathrm{s}-\mathrm{g} / \mathrm{s}-\mathrm{g} / \mathrm{s}$ & 0 & 1,11 & 16 [rra] s-g-g/s-s/gs & 4,35 & 13,33 \\
\hline 3. $[\mathrm{txa}] \mathrm{g}-\mathrm{s}-\mathrm{s} / \mathrm{s}-\mathrm{g} / \mathrm{s}$ & 2,17 & 0 & 17 [rra] s-g-g/s-s/s & 4,35 & 10 \\
\hline 4. $[\mathrm{ku}] \mathrm{s}-\mathrm{g}-\mathrm{s} / \mathrm{s}-\mathrm{g} / \mathrm{g}$ & 0 & 1,11 & 18 [sar] s-g-g/g-s/gs & - & - \\
\hline 5. $[\mathrm{ku}] \mathrm{s}-\mathrm{g}-\mathrm{s} / \mathrm{s}-\mathrm{g} / \mathrm{gs}$ & 0 & 1,11 & 19 [sar] s-g-g/g-s/s & 0 & 2,22 \\
\hline 6. $[\mathrm{ku}] \mathrm{s}-\mathrm{g}-\mathrm{s} / \mathrm{s}-\mathrm{g} / \mathrm{s}$ & 23,91 & 22,22 & 20 [sar] s-g-s/g-s/s & 2,17 & 0 \\
\hline 7. $[\mathrm{ku}] \mathrm{s}-\mathrm{g}-\mathrm{s} / \mathrm{s}-\mathrm{s} / \mathrm{g}$ & 0 & 1,11 & $21[\mathrm{tu}] \mathrm{s}-\mathrm{g}-\mathrm{s} / \mathrm{s}-\mathrm{g} / \mathrm{s}$ & 10,87 & 1,11 \\
\hline 8. $[\mathrm{ku}] \mathrm{s}-\mathrm{g}-\mathrm{s} / \mathrm{s}-\mathrm{s} / \mathrm{gs}$ & 0 & 6,67 & $22[\mathrm{tu}] \mathrm{s}-\mathrm{g}-\mathrm{g} / \mathrm{s}-\mathrm{g} / \mathrm{s}$ & - & - \\
\hline 9. $[\mathrm{ku}] \mathrm{s}-\mathrm{g}-\mathrm{s} / \mathrm{s}-\mathrm{s} / \mathrm{s}$ & 0 & 5,56 & $23[\mathrm{tu}] \mathrm{s}-\mathrm{g}-\mathrm{g} / \mathrm{g}-\mathrm{g} / \mathrm{s}$ & - & - \\
\hline 10. $[\mathrm{ku}] \mathrm{s}-\mathrm{g}-\mathrm{s} / \mathrm{g}-\mathrm{s} / \mathrm{gs}$ & - & & $24[\mathrm{tu}] \mathrm{s}-\mathrm{g}-\mathrm{g} / \mathrm{g}-\mathrm{g} / \mathrm{sg}$ & - & - \\
\hline 11 [rra] s-g-g/s-g/g & 2,17 & 1,11 & $25[\mathrm{tu}] \mathrm{s}-\mathrm{g}-\mathrm{g} / \mathrm{g}-\mathrm{gs} / \mathrm{gs}$ & - & - \\
\hline 12 [rra] s-g-g/s-g/gs & 13,04 & 3,33 & 26 [da] s-g-g/s-g/gs & - & - \\
\hline 13 [rra] s-g-g/s-g/s & 36,96 & 24,44 & 27 [da] s-g-g/s-s/gs & - & - \\
\hline 14 [rra] s-g-g/s-g/sg & - & - & & & \\
\hline
\end{tabular}

Orain arteko azterketak kontuan hartuta, ikusi dugu informatzaile batzuek emozio guztietan melodia bakarra erabiltzen dutela $(47, \% 34,56)$, beste batzuek melodia bi erabiltzen dituzte $(64, \% 47,06)$ eta beste batzuek emozio bakoitzeko melodia bat $(25, \% 18,38)$. Informatzaileen generoaren arabera portzentajeak 20. taulan agertzen diren eran banatzen dira (5. grafikoa).

\begin{tabular}{|l|r|c|r|c|}
\hline & \multicolumn{2}{|c|}{ M } & \multicolumn{2}{c|}{ N } \\
\hline & \multicolumn{1}{|c|}{ kop } & \multicolumn{1}{c|}{ \% } & kop & \% \\
\hline melodia bat (1) & 11 & 23,91 & 36 & 40,00 \\
\hline melodia bi (2) & 24 & 52,17 & 40 & 44,44 \\
\hline $\begin{array}{l}\text { hiru melodia } \\
\text { (3) }\end{array}$ & 11 & 23,91 & 14 & 15,56 \\
\hline
\end{tabular}

20. Taula: Informatzaileen sailkapena erabiltzen dituzten melodia kopuruen arabera.

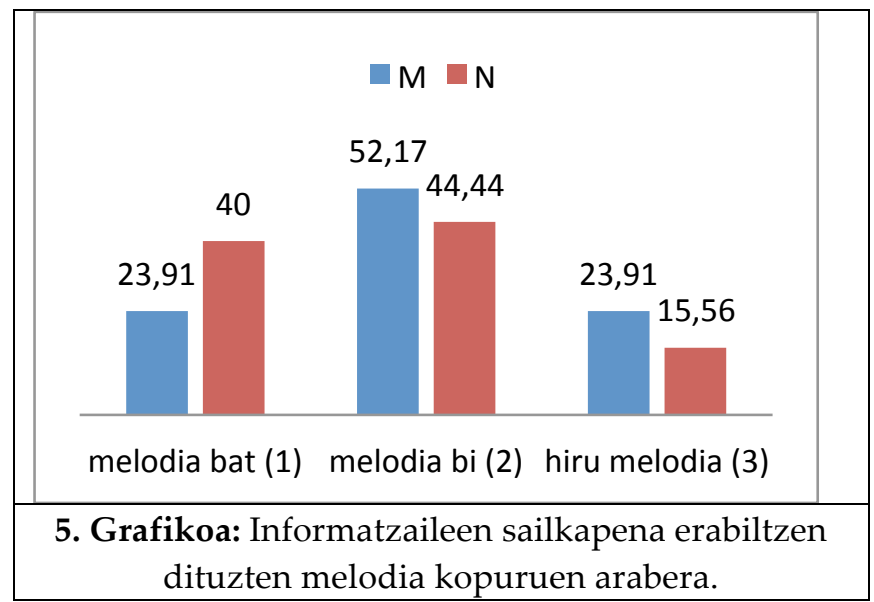

Datuak orokorrean aztertuta esan dezakegu nesken artean joera nabarmena dagoela melodia desberdinak erabiltzeko emozioak bereiztean. Neskek 180 melodia desberdin posibleetatik 158 erabiltzen dituzte $(\% 87,78)$ mutilek, ostera, 138 posibleetatik $92(\% 69,69)$ erabiltzen dituzte. 
Oinarrizko maiztasunaren batez bestekoa aztertzen badugu, ikus dezakegu ezen, altuena pozarekin gertatzen dela $(189,52 \mathrm{hz})$, gero haserrearekin $(183,29$ hz.) eta baxuena tristurarekin $(163,40$ hz.). 21 . taulan batez bestekoak $(\mathrm{X})$, desbiderapenak (sd), minimoak (min), maximoak (max) eta ibiltarteak (ibi) ikus daitezke (6. grafikoa). Batez bestekoetan agertzen diren aldeak estatistikoki esanguratsuak dira (askatasun mailak 2; F = 16,134; $\mathrm{p}=0,000$ ).

\begin{tabular}{|l|r|r|r|r|r|r|}
\hline \multicolumn{1}{|c|}{ Emozioa } & $\mathbf{N}$ & $\overline{\mathbf{X}}$ & $\mathbf{~ s d}$ & \multicolumn{1}{c|}{ min } & \multicolumn{1}{c|}{ max } & ibi \\
\hline haserrea & 136 & 183,30 & 39,03777 & 99,30 & 257,20 & 157,90 \\
\hline poza & 136 & 189,52 & 40,74840 & 107,39 & 255,13 & 147,75 \\
\hline tristura & 136 & 163,40 & 39,01094 & 86,30 & 230,18 & 143,88 \\
\hline \multicolumn{8}{|c|}{ 21. Taula: f0ren datuak emozioen arabera. } \\
\hline
\end{tabular}

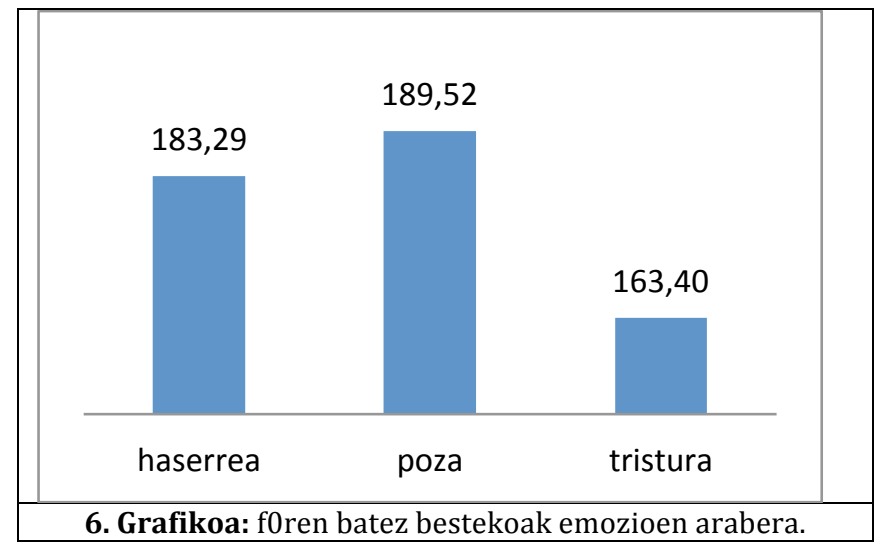

Datuak informatzaileen generoaren arabera aztertuz gero (22. taula), ikusten dugu mutilek f0ren batez besteko txikiagoak erabiltzen dituztela emozio guztietan (7. grafikoa). 22. taulan ANOVAren azterketak erakusten duen moduan, aldeak estatistikoki esanguratsuak dira kasu guztietan.

\begin{tabular}{|l|c|c|c|c|c|c|c|c|c|}
\hline & \multicolumn{4}{|c|}{ Mutilak } & \multicolumn{4}{c|}{ Neskak } & \multicolumn{3}{c|}{ ANOVA } \\
\hline Emozioa & $\mathbf{N}$ & $\overline{\mathbf{X}}$ & $\mathbf{s d}$ & $\mathbf{N}$ & $\overline{\mathbf{X}}$ & $\mathbf{~ s d}$ & a.m. & $\mathbf{F}$ & $\mathbf{p}$ \\
\hline poza & 46 & 138,72 & 20,91 & 90 & 215,48 & 16,80 & 1 & 536,342 & 0,000 \\
\hline tristura & 46 & 115,96 & 19,91 & 90 & 187,65 & 18,71 & 1 & 427,964 & 0,000 \\
\hline haserrea & 46 & 140,45 & 31,41 & 90 & 205,19 & 19,47 & 1 & 218,872 & 0,000 \\
\hline \multicolumn{4}{|c|}{ 22. Taula: f0ren datuak emozioen eta informatzaileen generoaren arabera. } \\
\hline
\end{tabular}

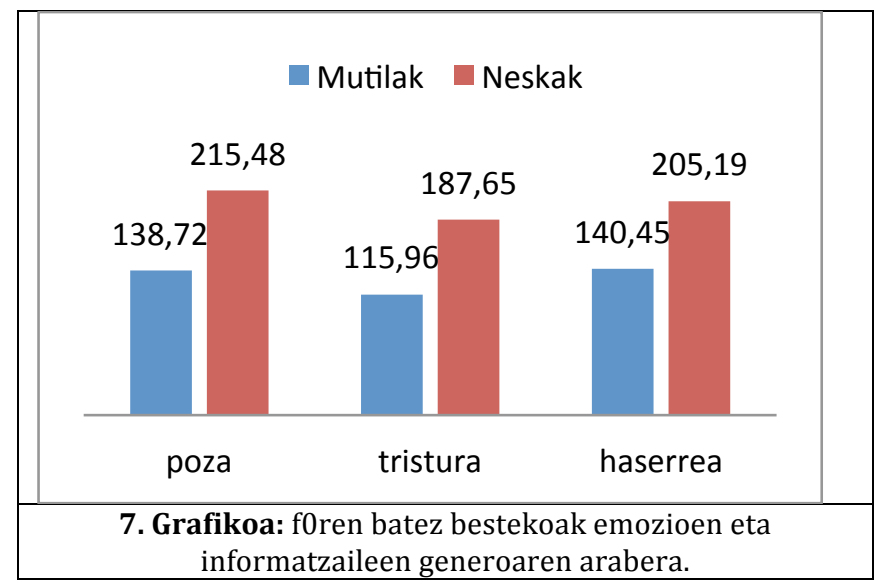


Oinarrizko maiztasunaren ibiltarteak aztertuta (23. taula eta 8. grafikoa), handiena pozarekin gertatzen da $(124,42 \mathrm{hz})$, gero haserrearekin $(103,08 \mathrm{hz}$.) eta txikiena tristurarekin (74,73 hz.). Batez bestekoetan agertzen diren aldeak estatistikoki esanguratsuak dira (askatasun mailak 2; $F=36,845, p=0,000$ ).

\begin{tabular}{|l|r|r|r|r|r|r|}
\hline \multicolumn{1}{|c|}{ Emozioa } & $\mathbf{N}$ & $\overline{\mathbf{X}}$ & $\mathbf{s d}$ & $\mathbf{m i n}$ & \multicolumn{1}{c|}{ max } & ibi \\
\hline haserrea & 136 & 103,08 & 48,76 & $-1,16$ & 229,45 & 230,62 \\
\hline poza & 136 & 124,42 & 47,03 & 40,03 & 236,77 & 196,74 \\
\hline tristura & 136 & 74,73 & 47,87 & $-25,49$ & 295,66 & 321,15 \\
\hline \multicolumn{8}{|c|}{ 23. Taula: f0ren ibiltarteen datuak emozioen arabera. }
\end{tabular}

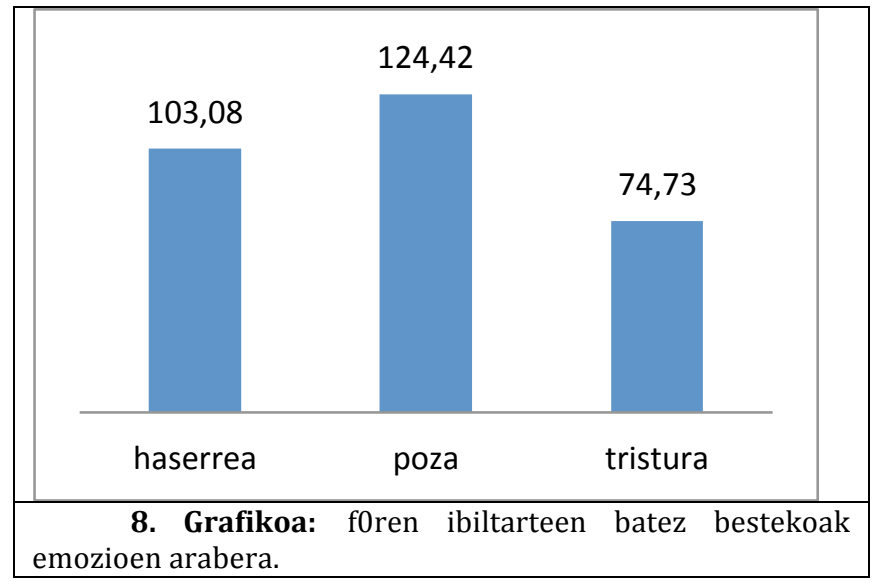

Datuak informatzaileen generoaren arabera aztertuz gero (24. taula), ikusten dugu mutilek ibiltarte txikiagoak erabiltzen dituztela emozio guztietan (9. grafikoa). 4. taulan ANOVAren azterketak erakusten duen moduan, aldeak estatistikoki esanguratsuak dira kasu guztietan.

\begin{tabular}{|l|r|r|r|r|r|r|r|r|c|}
\hline & \multicolumn{3}{|c|}{ Mutilak } & \multicolumn{3}{|c|}{ Neskak } & \multicolumn{3}{c|}{ ANOVA } \\
\hline Emozioa & N & $\overline{\mathbf{X}}$ & \multicolumn{1}{|c|}{ sd } & N & \multicolumn{1}{|c}{$\overline{\mathbf{X}}$} & sd & a.m. & \multicolumn{1}{|c|}{} & \multicolumn{1}{|c|}{ p } \\
\hline poza & 46 & 96,54 & 36,98 & 90 & 138,66 & 45,35 & 1 & 29,592 & 0,000 \\
\hline tristura & 46 & 52,32 & 57,86 & 90 & 86,18 & 37,310 & 1 & 17,033 & 0,000 \\
\hline haserrea & 46 & 88,52 & 49,81 & 90 & 110,52 & 46,75 & 1 & 6,448 & 0,012 \\
\hline \multicolumn{3}{|c|}{ 24. Taula: f0ren ibiltarteen datuak emozioen eta informatzaileen generoaren arabera. } \\
\hline
\end{tabular}

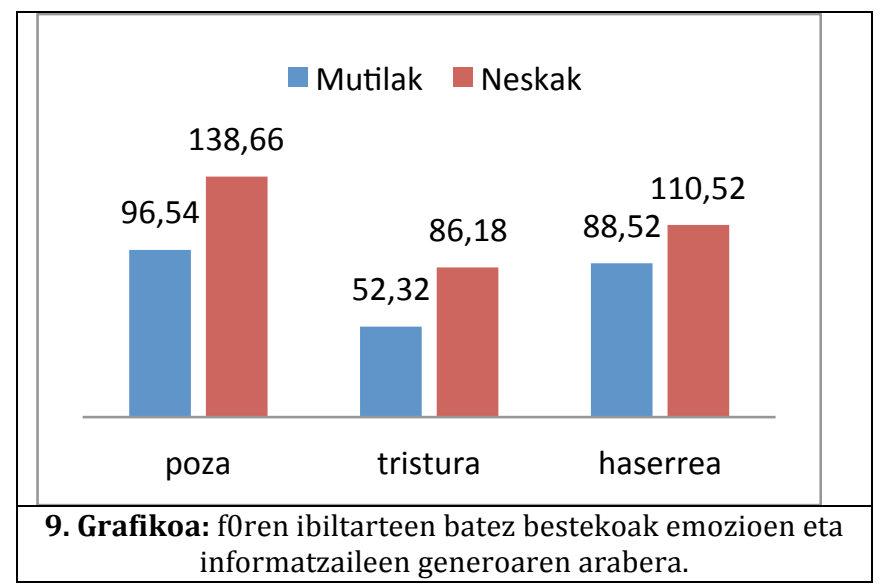




\subsection{Iraupenaren analisia}

Iraupenari dagokionez, neurri bi hartu ditugu kontuan; batetik esaldi osoaren iraupena eta, bestetik, esaldiaren azken silabaren iraupena.

Esaldiaren iraupen osoari dagokionez, luzeena tristura da $(869,41 \mathrm{~ms}$.$) ,$ gero haserrea $(847,94 \mathrm{~ms}$.) eta laburrena poza $(821,25 \mathrm{~ms}$ ); 25 . taulan datu guztiak laburbiltzen dira (10. grafikoa). Batez bestekoetan agertzen diren aldeak estatistikoki esanguratsuak dira (askagasun mailak 2; F =7,577; p =0,0012).

\begin{tabular}{|l|c|c|r|r|r|r|}
\hline \multicolumn{1}{|c|}{ Emozioa } & $\mathbf{N}$ & $\overline{\mathbf{X}}$ & sd & min & max & ibi \\
\hline haserrea & 136 & 847,94 & 97,97 & 660 & 1190 & 530 \\
\hline poza & 136 & 821,25 & 93,91 & 610 & 1070 & 460 \\
\hline tristura & 136 & 869,41 & 113,71 & 620 & 1440 & 820 \\
\hline \multicolumn{7}{|c|}{ 25. Taula: Esaldi osoaren iraupenaren datuak emozioen arabera. } \\
\hline
\end{tabular}

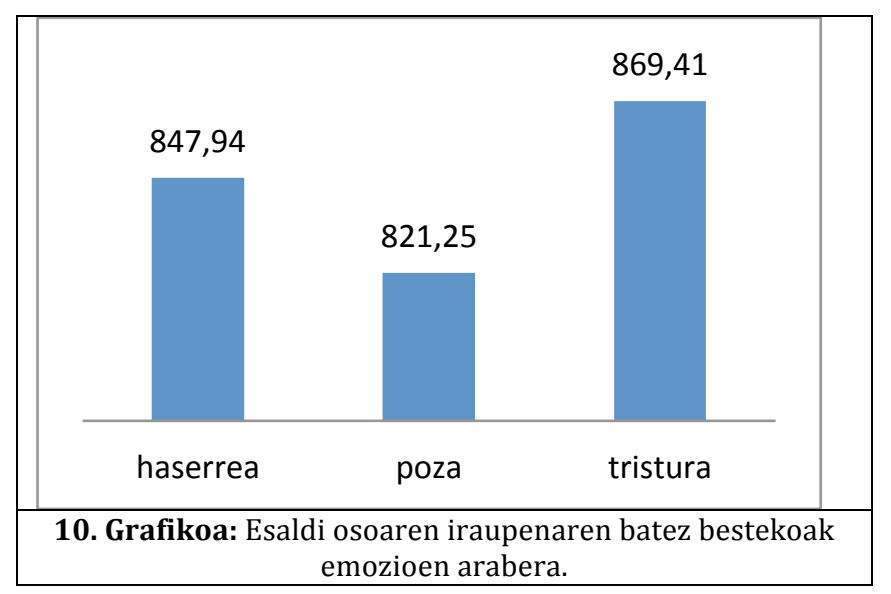

Datuak informatzaileen generoaren arabera aztertuz gero (26. taula), ikusten dugu mutilek laburrago egiten dituztela emozio guztietan (11. grafikoa). 26. taulan ANOVAren azterketak erakusten duen moduan, aldeak estatistikoki esanguratsuak dira kasu guztietan haserrearekin izan ezik.

\begin{tabular}{|l|r|c|r|r|r|r|r|r|r|}
\hline & \multicolumn{4}{|c|}{ Mutilak } & \multicolumn{3}{c|}{ Neskak } & \multicolumn{3}{c|}{ ANOVA } \\
\hline Emozioa & $\mathbf{N}$ & $\overline{\mathbf{X}}$ & sd & N & $\overline{\mathbf{X}}$ & sd & a.m. & \multicolumn{1}{c|}{ F } & p \\
\hline poza & 46 & 780,43 & 89,02 & 90 & 842,11 & 89,82 & 1 & 14,438 & 0,000 \\
\hline tristura & 46 & 829,57 & 107,83 & 90 & 889,78 & 111,78 & 1 & 9,044 & 0,003 \\
\hline haserrea & 46 & 825,22 & 91,69 & 90 & 859,56 & 99,51 & 1 & 3,818 & $* 0,053$ \\
\hline
\end{tabular}

2 a.m. = askatasun mailak, $\mathrm{F}=$ Fisher-en estatistikoa, $\mathrm{p}=$ probabilitatea. 


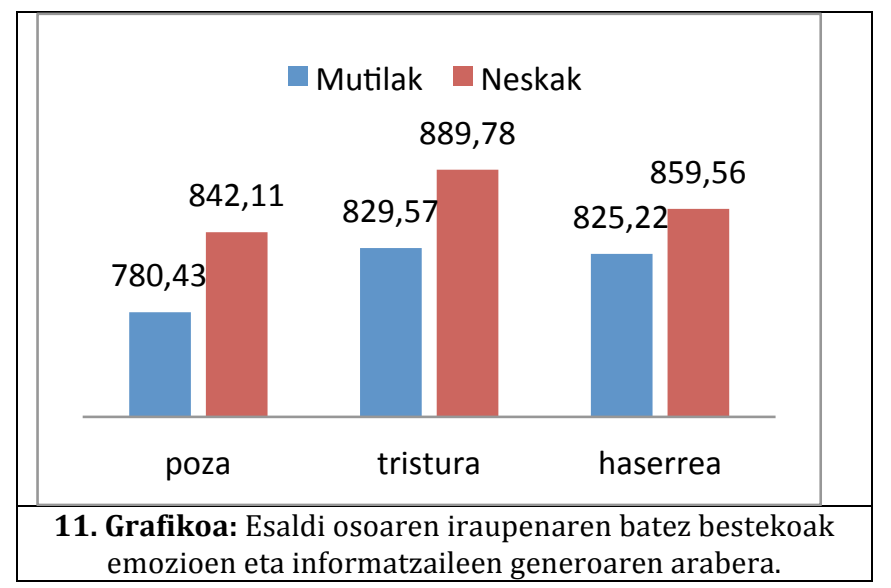

Esaldiaren iraupen osoaren azken silaba \%15,935koa da batez bestean. Mutilek arean luzeago $(\% 16,14)$ egiten dituzte neskek baino $(\% 15,83)$; hala ere, aldeak ez dira estatistikoki esanguratsuak (askatasun mailak 1; $\mathrm{F}=0,649$; $\mathrm{p}=0,421$ ).

Datuak emozioen arabera aztertzen baditugu (27. taula), ikusten dugu, azken silabarik luzeena pozarekin gertatzen dela, gero haserrearekin eta laburra tristurarekin (12. grafikoa); datu hauek estatistikoki esanguratsuak dira (askatasun mailak 2; $\mathrm{F}=16,826 ; \mathrm{p}=0,000$ ).

\begin{tabular}{|l|r|r|r|r|r|r|}
\hline & \multicolumn{1}{|c|}{$\mathbf{N}$} & \multicolumn{1}{c|}{$\mathbf{X}$} & \multicolumn{1}{c|}{ Sd } & \multicolumn{1}{c|}{ min } & \multicolumn{1}{c|}{ max } & \multicolumn{1}{c|}{ ibi } \\
\hline poza & 136 & 17,17 & 3,74 & 7,58 & 27,06 & 19,48 \\
\hline tristura & 136 & 14,73 & 3,15 & 6,02 & 22,62 & 16,60 \\
\hline haserrea & 136 & 15,90 & 3,51 & 8,54 & 25,29 & 16,75 \\
\hline
\end{tabular}

27. Taula: Esaldiaren azken silabaren iraupenaren portzentajeen datuak emozioen arabera.

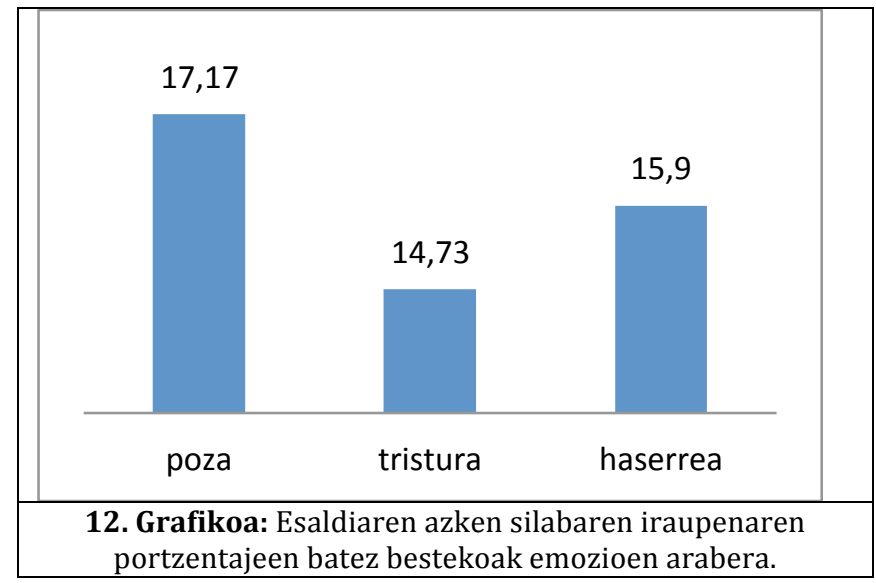

Emozioen datuak generoaren arabera aztertuz gero (28. taula), ikusten dugu mutilek arean laburrago egiten dituztela pozaren eta tristuraren azken silabak neskek baino; hala ere, aldeok ez dira estatistikoki esanguratsuak. Mutilek luzeago egiten dute azken silaba haserrearekin eta hau da estatistikoki esanguratsua den alde bakarra. 


\begin{tabular}{|l|r|c|c|r|c|c|r|r|r|}
\hline & \multicolumn{4}{|c|}{ Mutilak } & \multicolumn{3}{c|}{ Neskak } & \multicolumn{3}{c|}{ ANOVA } \\
\hline Emozioa & $\mathbf{N}$ & $\overline{\mathbf{X}}$ & $\mathbf{s d}$ & $\mathbf{N}$ & $\overline{\mathbf{X}}$ & sd & a.m. & \multicolumn{1}{c|}{ F } & p \\
\hline poza & 46 & 16,96 & 3,82 & 90 & 17,28 & 3,71 & 1 & 0,800 & ${ }^{*} 0,496$ \\
\hline tristura & 46 & 14,72 & 3,14 & 90 & 14,74 & 3,17 & 1 & 0,002 & $* 0,968$ \\
\hline haserrea & 46 & 16,73 & 3,91 & 90 & 15,47 & 3,24 & 1 & 3,979 & 0,048 \\
\hline
\end{tabular}

28. Taula: Esaldiaren azken silabaren iraupenaren portzentajeen datuak emozioen eta informatzaileen generoaren arabera.

\subsection{Energiaren analisia}

Energiaren azterketari dagokionez, berorren batez bestekoa eta ibiltartea aztertuko ditugu azpi-atal honetan.

Energiaren batez bestekoak emozioen arabera aztertzen baditugu (29. taula), ikusten dugu altuena pozarekin gertatzen dela $(73,95 \mathrm{db}$.), gero haserrearekin $(73,66 \mathrm{db}$.), alde hauek oso txikiak dira. Energiarik baxuena tristurarekin $(69,16 \mathrm{db}$.) gertatzen da (13. grafikoa). Batez bestekoetan agertzen diren aldeak, txikiak izan arren, estatistikoki esanguratsuak dira (askatasun mailak 2; $F=77,355 ; p=0,000$ ).

\begin{tabular}{|l|r|r|r|r|r|r|}
\hline \multicolumn{1}{|c|}{ Emozioa } & $\mathbf{N}$ & $\overline{\mathbf{X}}$ & \multicolumn{1}{c|}{ sd } & min & \multicolumn{1}{c|}{ max } & ibi \\
\hline haserrea & 136 & 73,66 & 3,26 & 64,59 & 81,11 & 16,52 \\
\hline poza & 136 & 73,95 & 3,10 & 62,75 & 80,24 & 17,50 \\
\hline tristura & 136 & 69,16 & 4,21 & 58,85 & 78,89 & 20,03 \\
\hline \multicolumn{8}{|c|}{ 29. Taula: Esaldiaren energiaren datuak emozioen arabera. } \\
\hline
\end{tabular}

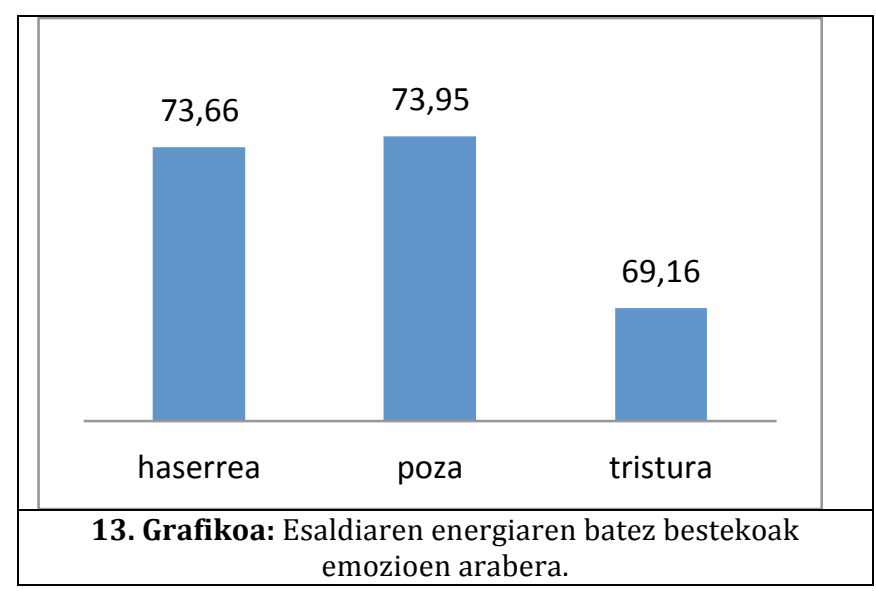

Datuak informatzaileen generoaren arabera aztertuz gero (30. taula), ikusten dugu mutilek energia altuagoak erabiltzen dituztela emozio guztietan (14. grafikoa). 4. taulan ANOVAren azterketak erakusten duen moduan, aldeak estatistikoki esanguratsuak dira kasu guztietan.

\begin{tabular}{|l|r|r|r|r|r|r|r|r|c|}
\hline & \multicolumn{4}{|c|}{ Mutilak } & \multicolumn{3}{c|}{ Neskak } & \multicolumn{3}{c|}{ ANOVA } \\
\hline Emozioa & $\mathbf{N}$ & $\overline{\mathbf{X}}$ & $\mathbf{s d}$ & $\mathbf{N}$ & $\overline{\mathbf{X}}$ & $\mathbf{s d}$ & $\mathbf{a . m .}$ & $\mathbf{F}$ & $\mathbf{p}$ \\
\hline poza & 46 & 74,67 & 3,037 & 90 & 73,57 & 3,09 & 1 & 3,954 & 0,049 \\
\hline tristura & 46 & 70,51 & 4,00 & 90 & 68,47 & 4,17 & 1 & 7,520 & 0,007 \\
\hline haserrea & 46 & 74,66 & 3,13 & 90 & 73,15 & 3,22 & 1 & 6,824 & 0,010 \\
\hline \multicolumn{8}{|c|}{ 30. Taula: Esaldiaren energiaren datuak emozioen eta informatzaileen generoaren arabera. } \\
\hline
\end{tabular}




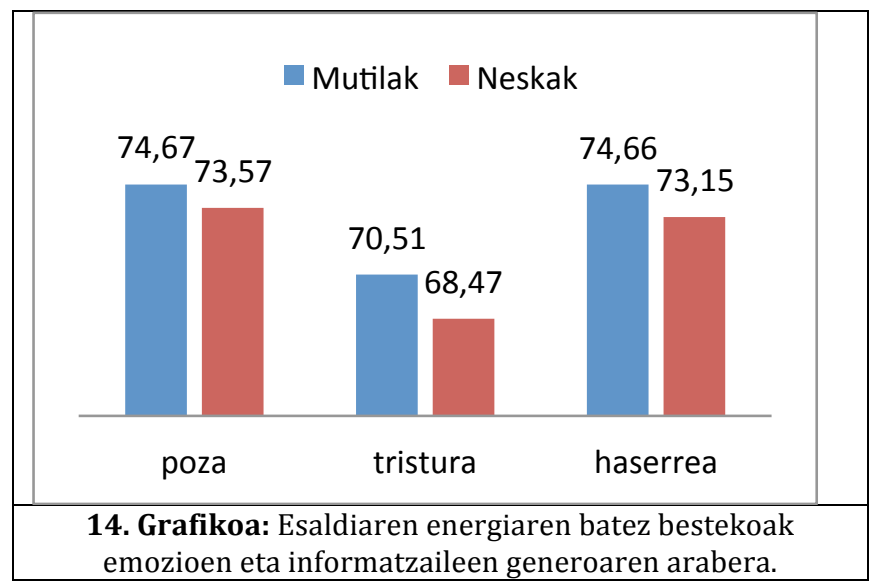

Energiaren ibiltarteak emozioen arabera aztertuz gero (31. taula eta 15. grafikoa), ikusten dugu handiena haserrearekin gertatzen dela (26,93 db.), gero pozarekin $(25,26 \mathrm{db}$.), eta txikiena tristurarekin (23,32 db.). Ibiltarteetan agertzen diren aldeak estatistikoki esanguratsuak dira (askatasun mailak 2; F= 22,992; $\mathrm{p}=0,000)$.

\begin{tabular}{|l|c|c|r|r|r|r|}
\hline \multicolumn{1}{|c|}{ Emozioa } & $\mathbf{N}$ & $\overline{\mathbf{X}}$ & \multicolumn{1}{c|}{ sd } & min & max & \multicolumn{1}{c|}{ ibi } \\
\hline haserrea & 136 & 26,93 & 4,45 & 15,79 & 38,30 & 22,51 \\
\hline poza & 136 & 25,26 & 4,00 & 12,66 & 36,03 & 23,37 \\
\hline tristura & 136 & 23,32 & 4,72 & 10,62 & 36,45 & 25,83 \\
\hline \multicolumn{7}{|c|}{ 31. Taula: Esaldiaren energiaren ibiltartearen datuak emozioen arabera. } \\
\hline
\end{tabular}

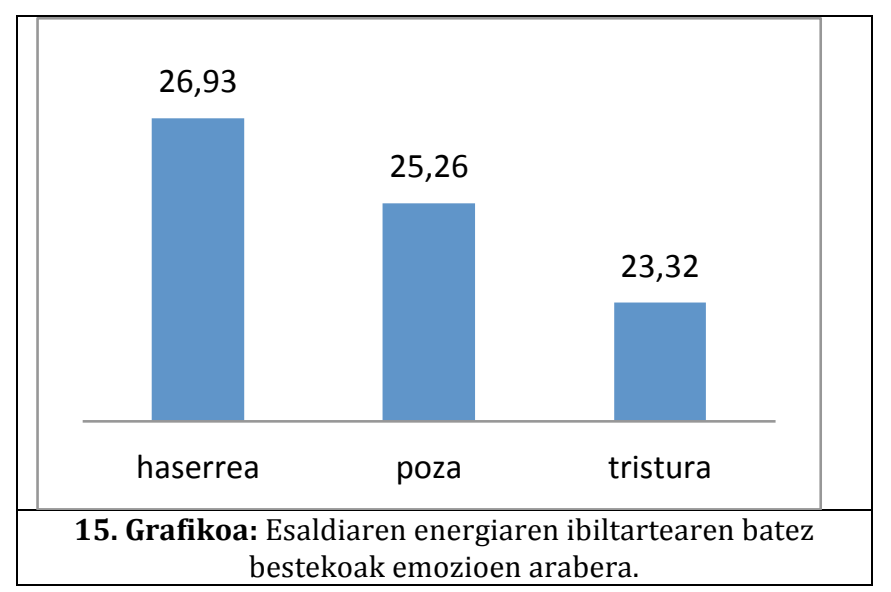

Datuak informatzaileen generoaren arabera aztertuz gero (32. taula), ikusten dugu neskek energia ibiltarte altuagoak erabiltzen dituztela mutilek baino emozio guztietan (16. grafikoa). 32. taulan ANOVAren azterketak erakusten duen moduan, aldeak estatistikoki esanguratsuak dira kasu guztietan tristuran izan ezik.

\begin{tabular}{|c|c|c|c|c|c|c|c|c|c|}
\hline & \multicolumn{3}{|c|}{ Mutilak } & \multicolumn{3}{|c|}{ Neskak } & \multicolumn{3}{|c|}{ ANOVA } \\
\hline Emozioa & $\mathbf{N}$ & $\overline{\mathbf{X}}$ & sd & $\mathbf{N}$ & $\overline{\mathbf{X}}$ & sd & a.m. & $\mathbf{F}$ & p \\
\hline poza & 46 & 23,19 & 3,56 & 90 & 26,32 & 3,80 & 1 & 21,543 & 0,000 \\
\hline tristura & 46 & 22,27 & 4,54 & 90 & 23,86 & 4,74 & 1 & 3,531 & $* 0,062$ \\
\hline haserrea & 46 & 24,95 & 4,52 & 90 & 27,95 & 4,08 & 1 & 15,268 & 0,000 \\
\hline
\end{tabular}




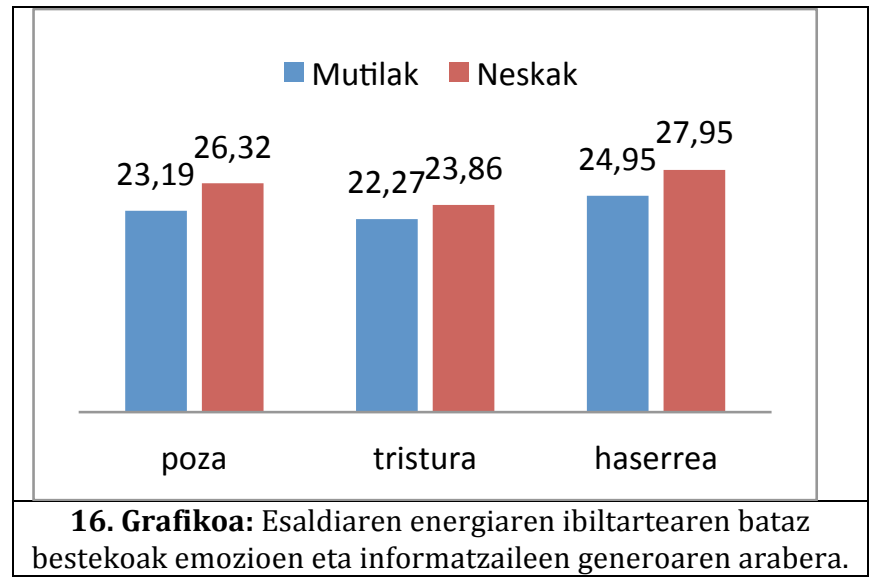

\subsection{Ahots kalitatearen analisia}

Ahots kalitateari dagozkion ahots murmurikatuaren eta karrankatuaren erabilera aztertzen da atal honetan. Azterketa horretarako bildu dugun corpusaren 408 esaldietatik ahots kalitatea (Ak) guztien \%36an erabiltzen da. Informatzileen generoaren araberako emaitzak aztertzen baditugu (33. taula), ikusten dugu orokorrean mutilek portzentaje altuagoa daukatela neskek baino, ahots kalitatearen erabilerari dagokionez (17. grafikoa). Khi karratuaren proba eginez gero, aldea estatistikoki esanguratsua da (balioa $=45,559$; astasun mailak $1 ; \mathrm{p}=0,000)$.

\begin{tabular}{|l|c|c|r|r|}
\hline & \multicolumn{2}{|c|}{ M } & \multicolumn{2}{c|}{ N } \\
\hline Ahots kalitatea & kopurua & ehunekoa & kopurua & ehunekoa \\
\hline +Ak & 80 & 57,97 & 67 & 24,81 \\
\hline -Ak & 58 & 42,03 & 203 & 75,19 \\
\hline \multicolumn{4}{|c|}{ 33. Taula: Ahots kalitatearen erabilera informatzaileen generoaren arabera. } \\
\hline
\end{tabular}

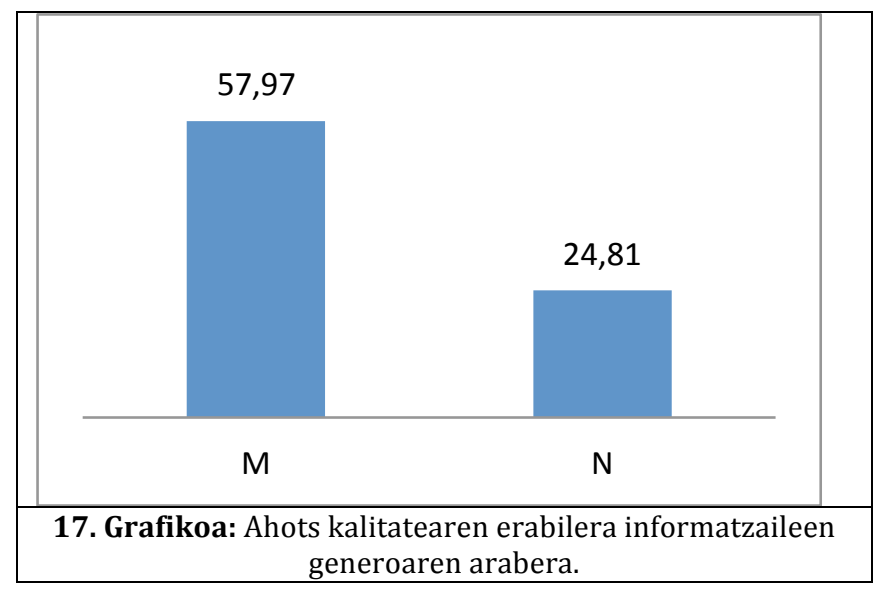

Esaldien datu orokorrak emozioen arabera aztertuz gero (34. taula), ikusten dugu ezen, aldeak estatistikoki esanguratsuak direla (balioa = 29,542; 
askatasun mailak 2; $\mathrm{p}=0,000)$. Ahots kalitatea gehien erabiltzen da tristurarekin, gero haserrearekin eta gutxien pozarekin (18. grafikoa).

\begin{tabular}{|l|r|r|r|r|r|r|}
\hline & \multicolumn{2}{|c|}{ Poza } & \multicolumn{2}{c|}{ Tristura } & \multicolumn{2}{c|}{ Haserrea } \\
\hline \multicolumn{1}{|c|}{ Ak } & kopurua & ehunekoa & kopurua & ehunekoa & \multicolumn{1}{l|}{ kopurua } & ehunekoa \\
\hline+ Ak & 28 & 20,59 & 71 & 52,21 & 48 & 35,29 \\
\hline -Ak & 108 & 79,41 & 65 & 47,79 & 88 & 64,71 \\
\hline \multicolumn{6}{|c|}{ 34. Taula: Ahots kalitatearen erabilera emozioen arabera. } \\
\hline
\end{tabular}

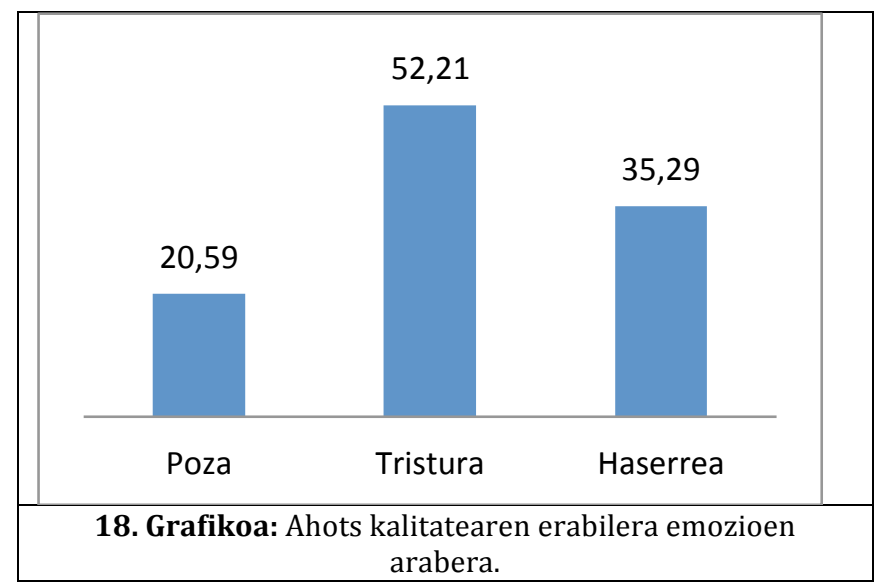

Ahots karrankatua gutxiagotan erabiltzen da $(\% 39,19)$ murmurikatua baino $(\% 60,81)$. Informatzaileen generoaren arabera aztertuz gero, 35 . taula osa dezakegu; bertan ikusten den moduan, aldeak oso txikiak dira. Agertzen diren aldeak ez dira estatistikoki esanguratsuak (balioa $=0,014$; askatasun mailak 1 ; $p$ $=0,906)$.

\begin{tabular}{|c|c|c|c|c|}
\hline & \multicolumn{2}{|c|}{$\mathbf{M}$} & \multicolumn{2}{|c|}{$\mathbf{N}$} \\
\hline Ahots kalitatea & kopurua & ehunekoa & kopurua & ehunekoa \\
\hline karrankatua & 31 & 38,75 & 27 & 39,71 \\
\hline murmurikatua & 49 & 61,25 & 41 & 60,29 \\
\hline
\end{tabular}

Datuak emozioen arabera aztertuta (36. taula), ikusten dugu alde nabarmenak agertzen direla. Pozarekin ahots kalitatea erabiltzen den kasu gehiagotan erabiltzen da karrankatua murmurikatua baino, antzera gertatzen da haserrearekin; baina, tristurarekin askoz gehiagotan erabiltzen da murmurikatua karrankatua baino. Khi karratuaren proba eginez gero, agertzen diren aldeak estatistikoki esanguratsuak dira (balioa $=36,139$; askatasun mailak $2 ; \mathrm{p}=0,000)$.

\begin{tabular}{|c|c|c|c|c|c|c|}
\hline & \multicolumn{2}{|c|}{ Poza } & \multicolumn{2}{|c|}{ Tristura } & \multicolumn{2}{|c|}{ Haserrea } \\
\hline Mota & kopurua & ehunekoa & kopurua & ehunekoa & kopurua & ehunekoa \\
\hline karrankatua & 17 & 60,71 & 10 & 14,08 & 31 & 63,27 \\
\hline murmurikatua & 11 & 39,29 & 61 & 85,92 & 18 & 36,73 \\
\hline
\end{tabular}




\section{ONDORIOAK}

Atal honetan aurrekoan egin dugun datuen analisitik atera daitezkeen ondoriorik garrantzitsuenak laburbilduko ditugu. Horretarako aztertu ditugun ezaugarri akustiko guztiekin, emozioen arabera, generoak eragin esanguratsua zenbat kasutan eduki duen ikusiko dugu.

Aztertu ditugun emozioen araberako ezaugarri akustikoak, blokeka antolatuta, honako hauek izan dira:

F0:

(1) Esaldiaren melodietan gailur prosodikoa kokatzen den silaba

(2) Lehen sintagmaren melodiak emozioen arabera

(3) Bigarren sintagmaren gorputzaren melodiak emozioen arabera

(4) Azken silabaren tonu gorabeherak emozioen arabera

(5) Esaldi osoaren melodiak

(6) f0ren batez bestekoa

(7) f0ren ibiltartea

Iraupena:

(8) Esaldi osoaren iraupena

(9) Esaldiaren azken silabaren iraupena

Energia:

(10) Energiaren batez bestekoa

(11) Energiaren ibiltartea

Ahots kalitatea:

(12) Ahots kalitatearen erabilera orokorra

(13) Ahots murmurikatuaren erabilera emozioen arabera

(14) Ahots karrankatuaren erabilera emozioen arabera

37. taulan erakusten dugu generoa emozio bakoitzeko zein kasutan den esanguratsua eta zeinetan ez.

\begin{tabular}{|c|c|c|c|}
\hline & Poza & Tristura & Haserrea \\
\hline (1) & - & - & - \\
\hline (2) & - & - & - \\
\hline (3) & - & - & + \\
\hline (5) & - & - & - \\
\hline (6) & - & - & + \\
\hline (7) & + & + & + \\
\hline (8) & + & + & - \\
\hline (9) & + & + & + \\
\hline (10) & - & + & + \\
\hline (11) & + & - & + \\
\hline (12) & + & + & + \\
\hline (13) & + & - & - \\
\hline (14) & - & - & - \\
\hline
\end{tabular}


37. taula aztertuz gero, ikusten dugu 19 kasutan (\%45,24an) generoak aldeak eragiten dituela esanguratsuki. Esaldiaren melodiei eta euron osagaiei dagokienez, generoak eragineko aldea \%13,33koa da. Haatik, f0ren batez bestekoari eta ibiltarteari dagokienez, aldea \%100koa da; alde hau informatzaileen sexuak eragineko desberdintasun biologikoetan oinarritzen da (ikusi autorea, 2010). Iraupenean gertatzen diren aldeak esanguratsuak dira \%50ean. Energiaren aldeak \%83,33an eta ahots kalitatean gertatzen direnak $\% 33,33$ an.

Ahots kalitatearen erabilera orokorrari dagokionez, eta generoa kontuan izanik, datuek adierazten dutenaren arabera, mutilek neskek baino portzentaje altuagoan erabiltzen dute, eta emaitzetan ikus daitekeen bezala, aldea estatistikoki esanguratsua da, beraz, genero identitateak ahots kalitatea erabiltzeko orduan eragin esanguratsua duela esan daiteke. Bestetik, ahots karrankatua eta murmurikatua erabiltzean, ez dago ezberdintasun esanguratsurik generoaren arabera, izan ere, datuetan islatzen denez, neskek eta mutilek antzera erabiltzen dute, murmurikatua karrankatua baino gehiagotan erabiliz batzuek zein besteek. Kasu honetan, ahots-kalitate mota ez dela genero identitate ezberdina azpimarratzeko esanguratsua ikus daiteke. Hala ere, adierazgarria da, murmurikatua gehiagotan erabiltzen dutela, beharbada, Biemans-ek (2000) aipatzen zuen identitate sozialarekin izan dezake zerikusia, ildo honetatik etorkizunerako lan gisa, interesgarria izango litzateke gazteen artean pertzpezio-testak egitea adierazitakoa baieztatzeko ala ezeztatzeko.

Aurreko 37. taula aztertuz gero, ikusten dugu lau kasutan (F0ren batez bestekoan, F0ren ibiltartean, energiaren batez bestekoan, ahots kalitatearen erabilera orokorrean) generoak aldeak eragiten dituela esanguratsuki emozioen adierazpenean. Bestalde, sexuak eragineko alde biologikoetan oinarritzen diren alde fisiko hutsez gain, badira beste alde batzuk, hala nola ahots kalitatearen erabileraren aldea faktore sozialek eraginekoak direnak.

\section{BIBLIOGRAFIA}

AMBRUŠ, D. C. (2000), «Collecting and recording of an emotional Speech database» Technical Report, Faculty of Electrical Engineering and Computer Science, Institute of Electronics, University of Maribor.

ARRETXE, J. (1994), Basauriko euskara, Basauri, Basauriko Udala.

BABEL, M. Social judgements and their acoustic cues in read speech [en línea]. UC Berkeley Phonology Lab Annual Report 2007 [Consulta: 15 julio 2013]. Disponible a: $<$ http://linguistics.berkeley.edu/phonlab/annual_report/documents/2007/Babel_g ay.pdf>

BARRUTIA, E. (1996), Bermeo eta Mundakako arrantzaleen hiztegia, Iruña, Udako Euskal Unibertsitatea. 
BIEMANS, M. (2000), Gender variation in voice quality, Tesis Doctoral. LOT Dissertation Series 38.

BOERSMA, P. eta WEENINK, D. Praat: doing phonetics by computer (Version 5.1) [programa d'ordinador]. Descarregat el 31 gener 2009, a <http://www.praat.org/> [Consulta: 1 juliol 2013].

CANEPARI, L. (2007), Fonetica e Tonetica Naturali: Approccio articolatorio, uditivo e funzionale, München, Lincom Textbooks in Linguistics.

CHARfuElan, M.; SCHRÖDER, M. Y STEINER, I. «Prosody and voice quality of vocal social signals: the case of dominance in scenario meetings», Proc. Interspeech [En línia] Japan: Makuhari, 2010 [Consulta: 3 juliol 2013]. Disponible a: <http://www.dfki.de/ charfuel/papers/charfuelan_etal2010.pdf >

CHUN, E Y PODESVA, R. J. (2010), «Voice quality and indeterminacies of social meaning in constructed dialogue», Paper presented at Sociolinguistics Symposium 18, Southampton.

GAMINDE, I. (2007), Bizkaian zehar. Euskararen ikuspegi orokorra, Bilbao, Mendebalde Kultura Alkartea.

GAMINDE, I. (2010), Bizkaiko Gazteen Prosodiaz: Euskaraz eta Gaztelaniaz, Bilbao, Mendebalde Kultura Alkartea eta Bizkaiko Foru Aldundia.

GAMinde, I.; Romero, A. ETA LegARRA, H. (2012), Gramatika eta Hizkuntz Bariazioa Bermeon, Bermeo, Bermeoko Udala eta Campos Hegaluzea.

GAMINDE, I. ETA ROMERO, A. (2011) “Genero eta adina Bermeoko berbaldiaren fonemen eta hotsen frekuentzian", Fontes Linguae Vasconum, 113, 115-138.

GAMinde, I.; GARAy, U.; ETXEBARRIA, A.; ROMERO, A. (2013A), “Oinarrizko emozioen melodiez", Euskalingua, 23, 14-27.

GAMinde, I.; ETXEBARriA, A. ETA GARAY, U., ROMERO, A. (2013B), “Ahots kalitatearen erabilera oinarrizko emozioak adierazteko", Ikastorratza e-Revista de Didáctica, 11, 1-11.

GARCíA-LeIVA, P. «Identidad de género: Modelos explicativos», Escritos de PsicologíaPshychological writings [En línia]. Málaga: Universidad de Málaga, 2005 [Consulta: 6 setembre 2013]. Disponible en: <www.redalyc.org/pdf/2710/271020873007.pdf>

HARNESS GOODWIN, M., GOODWIN, CH. eta YAEGER-DROR, M. (2002), «Multi-modality in girls' game disputes», Journal of Pragmatics, 34, 1621-1649.

KeAtiNG, P.A. Linguistic voice quality [En línea]. UCLA Voice Projects [Consulta: 4 de juliol de 2013]. Disponible a: $<$ http://www.phonetics.ucla.edu/voiceproject/voice.html $>$

LEFKOWITZ, D. (2007), "Creaky Voice: Constructions of Gender and Authority in American English Conversation», Paper presented at American Anthropological Association, Washington, DC.

Liscombe, J. (2007), Prosody and Speaker State: Paralinguistics, Pragmatics, and Proficiency, Doktorego Tesia, Columbia University.

LopeZ, Q. (2010), «I Ain't Lying': The Role of Voice Quality in Constructing (in)Authentic Identity», Paper presented at New Ways of Analyzing Variation, San Antonio.

Makarova, V. eta Petrushin V.A. (2003), Phonetics of Emotion in Russian Speech, Chicago, Accenture Technology Labs. 
MENDOZA-DENTON, N. (2007), "Creaky voice in gang girl narratives», Paper presented at the Annual Meetings of the American Anthropological Association, Washington, DC.

Mesut Meral, HaZim K. Ekenel, A. Sumru Özsoy. «Role of Intonation Patterns in Coveying Emotion in Speech», Proceedings of 17th NationalConference on Turkish Linguistics [En línea]. Boğaziçi Üniversitesi, 2002, [Consulta: 15 juliol 2013]. Disponible a: $<$ http://citeseerx.ist.psu.edu/viewdoc/download?doi=10.1.1.21.6077\&rep=rep1\&ty pe $=$ pdf $>$

National Center for Voice And SPeech. Vocal Fold Oscillation [En línea]. The University of Utah [Consulta: 11 juliol 2013]. Disponible a: <http://ncvs.org/elearning/equations/chapter4/index.html>

NoOteвоOM, S. (1997), «Prosody of speech: melody and rhythm» in The Hand book of Phonetics Sciences, Hardcastle, W. J. eta Laver, J., Oxford, Blackwell.

PoDESVA, R. J. (2007), «Phonation type as a stylistic variable: The use of falsetto in constructing a persona», Journal of Sociolinguistics, 11, 478-504.

Podesva, R. J. Gender and the Social Meaning of Non-Modal Phonation Types [en línea].Proceedings of the 37th Annual Meeting of the Berkeley Linguistics Society (2013) [Consulta: 12 juliol 2013]. Disponible a: $<$ http://www.stanford.edu/ podesva/documents/bls2011-4up.pdf $>\quad$ [2013ko uztailean kontsultatua

SEPPÄNEN, T., TOIVANEN, J. eta VÄYRYNEN, E. MediaTeam Speech Corpus: a first large Finnish emotional speech database [En línea]. MediaTeam, University of Oulu Finland [Consulta: 5 juliol 2013]. Disponible a: $<$ http://www.mediateam.oulu.fi/publications/pdf/>

SICOLI, M. (2010), «Shifting voices with participant roles: Voice qualities and speech registers in Mesoamerica», Language in Society, 39, 521-553.

StUART-SMiTH, J. (1999), "Glasgow: Accent and voice quality», in Urban Voices: Accent Studies in the British Isles, Foulkes P. eta Docherty G. (eds.), London, Arnold, pp. 203-222.

SZAKAY, A. (2008), «Ethnic variation in voice quality in New Zealand English», Paper presented at New Ways of Analyzing Variation 37, Houston.

TAlbOT, M. (2010), Language and Gender, Malden, Polity Press.

YUASA, I. P. (2010), «Creaky voice: A new feminine voice quality for young urbanoriented upwardly mobile American women?», American Speech, 85, 315-337.

ZUBILlaGA, H. eta GAMINDE, I. (2010), «/t/ren palatalizazioa Lekeitioko euskaran», Ikastorratza, 3, 1-9. 